\title{
Os aspectos geológicos do Maciço Santa Angélica (ES): uma nova abordagem
} The geology of Santa Angelica's intrusion: a new argument

Marcela Lopes Zanon ${ }^{1 *}$, Alexandre de Oliveira Chaves ${ }^{1}$, Caio Vinícius Gabrig Turbay Rangel ${ }^{2}$, Leonan Gaburo ${ }^{3}$, Carlos Roberto Pires ${ }^{3}$

RESUMO: O Maciço Santa Angélica (CISA) está localizado na região sul do Espírito Santo e corresponde a um dos corpos intrusivos mais importantes da Supersuíte G5 associada ao estágio pós-colisional do Orógeno Araçuaí. Ele é constituído por dois núcleos gabroicos e bordas félsicas, estas separadas por uma extensa zona de mistura de magmas. Suas rochas encaixantes fazem parte da Supersuíte G1 (fase pré-colisional) e do Grupo Bom Jesus do Itabapuana (antigo Complexo Paraíba do Sul). A fim de compreender os possíveis processos de dinâmica físico-química entre o magmatismo máfico e félsico desse maciço, bem como suas possíveis relaçóes com sua borda ortoderivada (G1), foram realizados estudos de campo, petrográfico, litogeoquímico e em microssonda eletrônica. A análise dos dados confirmou o modelo tectono-magmático proposto pela literatura e indicou novas informaçôes: as zonas de cisalhamento dextrais regionais favoreceram a entrada desse corpo intrusivo, dando a ele uma forma alongada e sigmoidal e causando a deformaçâo dos gnaisses do G1. Sua formaçáo foi acompanhada de processos de diferenciação magmática (cristalização fracionada) e da geração de uma extensa zona de mistura mecânica de magmas (mingling).

PALAVRAS-CHAVE: Maciço Santa Angélica; Supersuíte G5; Supersuíte G1.

\begin{abstract}
The Santa Angelica's Intrusion (CISA), located in the southern Espirito Santo state, is one of the most important intrusion bodies of the G5 Supersuite (Araçuai Orogen post-collisional stage). This is constituted by two gabbroic nucleus and a felsic border with a magma mingling zone and was emplaced into G1 Supersuite rocks (pre-collisional stage) and into rocks from the Bom Jesus do Itabapuana Group. The processes of physical and chemical dynamic of mafic and felsic magmatism of the CISA and the gneiss margin (G1 Supersuit) is studied herein. In order to do this, fieldwork, petrographic microscopic study, microprobe analysis and geochemical analyses were realized. The interpretation of this data resulted in a tectono-magmatic model that explains the structural control of the main deformation phases associated the G1 Supersuite's rocks and how they influenced the process of intrusion and shaping the CISA from regional shear zones. Was shown the magmatic differentiation process (fractional crystallization) involving the two gabbroic's nucleus of the $G 5$ and the most important aspects of the magma mingling zone.
\end{abstract}

KEYWORDS: Santa Angelica's Intrusion; G5 Supersuit; G1 Supersuit.

'Universidade Federal de Minas Gerais - UFMG, Belo Horizonte (MG), Brasil.E-mail: zanon.marcela@gmail.com, alochaves@yahoo.com.br ${ }^{2}$ Universidade Federal do Espírito Santo - UFES, Campus Alegre, Alegre (MG), Brasil. E-mail: turbay@cca.ufes.br

${ }^{3}$ Instituto Federal de Educação, Ciência e Tecnologia do Espírito Santo - IFES, Campus Cachoeiro de Itapemirim, Cachoeiro do Itapemirim (ES), Brasil. E-mail: leonangaburo@gmail.com,carlosr@ifes.edu.br

*Autor correspondente.

Manuscrito ID: 20150005. Recebido em: 04/06/2015. Aprovado em: 23/10/2015. 


\section{INTRODUÇÃO}

O Maciço Santa Angélica (CISA) consiste em um corpo intrusivo de aproximadamente $200 \mathrm{~km}^{2}$, localizado na regiáo sul do Espírito Santo, e faz parte da chamada Supersuíte G5, gerada durante o estágio pós-colisional $(530$ - $490 \mathrm{Ma})$ do Orógeno Araçuaí (Bayer et al. 1987, Schmidt-Thomé e WeberDiefenbach 1987, Wiedemann et al. 1987, Wiedemann et al. 1997, Wiedemann-Leonardos et al. 2000, Pedrosa-Soares et al. 2011). Tal intrusão apresenta bordas essencialmente félsicas e dois núcleos máficos separados por uma extensa zona de mistura de magmas (Fig. 1).

Suas rochas encaixantes são representadas por ortognaisses da Supersuíte G1 e, em menor proporção, por paragnaisses do Grupo Bom Jesus do Itabapuana (antigo Complexo Paraíba do Sul) (Bayer et al. 1987, CPRM 2013). A Supersuíte G1 foi gerada durante o estágio pré-colisional $(630$ - $585 \mathrm{Ma})$ do Orógeno Araçuaí (também conhecido como acrescionário) (Pedrosa-Soares \& Wiedemann-Leonardos 2000, PedrosaSoares et al. 2001, 2007, Silva et al. 2005, Pedrosa-Soares et al. 2011), sendo constituída por tonalito e granodiorito, e, em menor proporção, por granito e diorito (Pedrosa-Soares et al. 2001, Martins et al. 2003). Tais rochas apresentam bandamento gnáissico, localmente mostram-se milonitizadas e são originadas a partir de magmas cálcio-alcalinos, metaluminosos a peraluminosos, formados em ambiente de arco vulcânico (Geiger 1993, Campos-Neto e Figueiredo 1995, Wiedemann et al. 1997, Pedrosa-Soares et al. 1999, Martins et al. 2003, Campos et al. 2004, Nalini et al. 2005). $\mathrm{Na}$ área de estudo, além do granodiorito, foram registradas intrusóes de gabro (divididos em duas fases, sendo a mais velha constituída por xenólitos da rocha hospedeira).

A Supersuíte G5 é dividida em dois estágios: precoce (constituído pela fase charnoquítica) e final (associado a magmatismo bimodal), ambos gerados durante o colapso extensional do estágio pós-colisional, entre 535 e $480 \mathrm{Ma}$ (Wiedemann-Leonardos et al. 2000). Essas intrusões podem ser classificadas em três séries magmáticas: toleítica, cálcio-alcalina e alcalina, esta última formada por granitoides metaluminosos, de alto potássio, originados na crosta continental média a inferior com contribuição mantélica (Horn \& Weber-Diefenbach 1987, Mendes et al. 1997, Ludka et al. 1998, Medeiros et al. 2000, Wiedemann-Leonardos et al. 2000, Wiedemann 2003, Pedrosa-Soares et al. 2011).

O magmatismo presente no CISA é caracterizado por um zonamento inverso concêntrico resultante da sua composição bimodal, formada pela alternância de magmas félsicos (sienomonzonitos a granitos) nas bordas e por dois núcleos máficos (dioritos a gabros). $\mathrm{O}$ contato entre essas

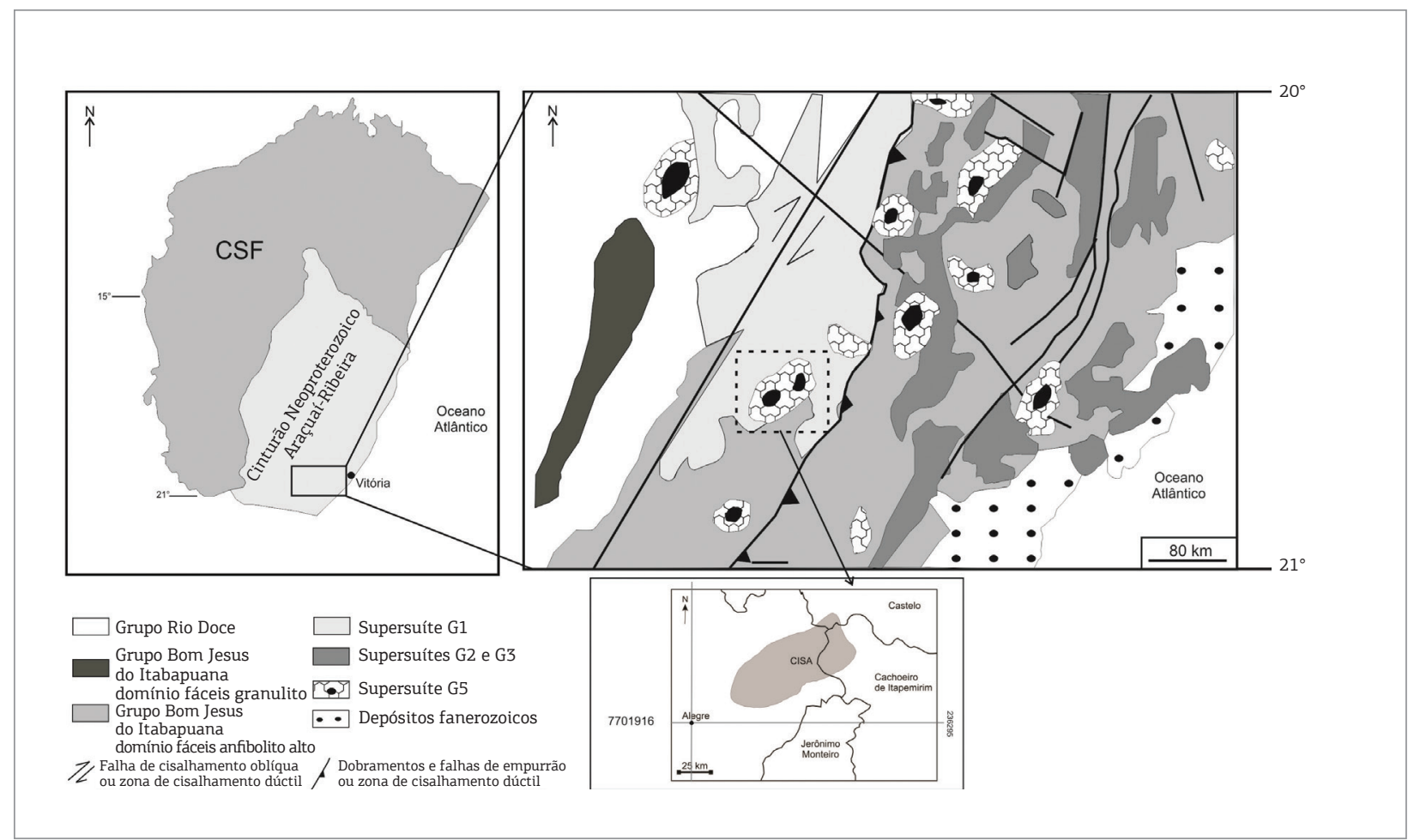

Figura 1. Mapa regional da área de estudo. O Maciço Santa Angélica está inserido nos municípios de Alegre, Cachoeiro de Itapemirim e Castelo, na região sul do Espírito Santo. Adaptado de Campos et al. 2004, Alkmin et al. 2006, Pedrosa-Soares et al. 2007. 
rochas é marcado por uma extensa zona de mistura de magmas (Schmidt-Thomé e Weber-Diefenbach 1987, Bayer et al. 1987, Wiedemann et al. 1987, 1997, WiedemannLeonardos et al. 2000). Söllner et al. (2000) determinaram a idade U-Pb em zircóes para o CISA de $513+/-8 \mathrm{Ma}$ (granito de granulaçáo grossa de tipo I) e $492+/-15 \mathrm{Ma}$ (granito fino tardio de tipo II).

O contato entre as rochas encaixantes (foliação vertical a subvertical) e o maciço sugere que seu mecanismo de intrusão ocorreu a partir de processos como o diapirismo, parcialmente controlados pelas zonas de cisalhamento presentes na área (Weinberg et al. 2004 apud Campos et al. 2004), dentre elas a zona de cisalhamento Guaçuí.

Neste artigo discutem-se os possíveis processos de dinâmica físico-química do magmatismo máfico e félsico do CISA e sua relação com a encaixante ortoderivada sob diferentes condiçôes de stress tectônico durante os estágios pré e pós-colisional. Essas informaçóes foram obtidas por meio de estudos de campo, petrográfico, de litogeoquímica e análises em microssonda, desenvolvidos a partir da dissertaçáo de mestrado do primeiro autor (Zanon 2013).

\section{MATERIAIS E MÉTODOS}

O desenvolvimento da pesquisa contou com revisão bibliográfica detalhada sobre os assuntos abordados, trabalhos de campo, estudo petrográfico microscópico, análises em microssonda e litogeoquímica.

As campanhas de campo dividiram-se em duas fases: a primeira objetivou a descrição geológica detalhada dos afloramentos-chave que expóem as interaçóes entre os magmas máficos e félsicos e a coleta de amostras, enquanto a segunda teve enfoque na análise estrutural regional. Durante os campos foram descritos 39 pontos de interesse e coletadas 61 amostras. Das amostras coletadas, 49 foram utilizadas na confecção de lâminas delgadas aplicadas ao estudo petrográfico e em microssonda eletrônica, enquanto 29 destinaramse à análise litogeoquímica.

O estudo em microssonda eletrônica foi realizado no Laboratório de Microanálise do Departamento de Física da Universidade Federal de Minas Gerais (UFMG) a partir da análise de seis amostras portadoras de xenocristais de K-feldspato localizadas na zona de mistura de magmas. Os resultados foram interpretados com o auxílio do programa Minpet (Richard 1996).

As amostras destinadas à litogeoquímica foram preparadas no Laboratório de Preparação de Amostras do Departamento de Geologia da Universidade Federal do Espírito Santo (UFES) e posteriormente enviadas para a SGS GEOSOL
Laboratórios LTDA., para a análise dos elementos maiores e traços, incluindo os elementos terras raras (ETR), por ICPOES e ICPMS. Os resultados possibilitaram a confecção de diagramas litogeoquímicos com o auxílio do programa GeoPlot (Zhou \& Liu 2006).

\section{RESULTADOS}

\section{Aspectos de campo e petrografia}

Nas atividades de campo foram catalogadas quatro unidades litoestratigráficas principais: Grupo Bom Jesus do Itabapuana e Supersuíte G1 como rochas encaixantes, Supersuíte G5 e rocha leucocrática tardia, das quais apenas as três últimas estão detalhadas nas demais etapas deste trabalho (Fig. 2).

As rochas da Supersuíte G1 foram cartografadas em dois litotipos: metagranodiorito e metaquartzo biotita hornblenda gabro. O primeiro (Figs. 3A e 3C) ocorre na forma de pequenos maciços rochosos, apresenta foliação milonítica com trend preferencial NE/SW e sigmoides que chegam a ter até $1,5 \mathrm{~m}$ de comprimento, indicando movimento dextral predominante. Já o metaquartzo biotita hornblenda gabro ocorre na forma de corpos tabulares. A relação de corte entre essas intrusóes bem como suas características possibilitaram definir uma fase mais antiga (com enclaves de metagranodiorito) e outra mais tardia (Figs. $4 \mathrm{~B}$ e C). Os enclaves mostram-se alongados e dispostos segundo a direção do plano $S$ (descrito adiante).

Em dois dos afloramentos estudados ocorrem estruturas S-C (Fig. 4) onde a superfície C, disposta preferencialmente a NE/SW, faz um ângulo aproximado de 20 a $35^{\circ} \mathrm{com}$ a superfície $S$ e suas relaçóes indicam movimento dextral. Nesses mesmos pontos também são descritas falhas transcorrentes (associadas ao trend de C) que, ao cortar os corpos intrusivos máficos, possibilitam a entrada de novas intrusôes ígneos/metaígneos de menor dimensão (Fig. 4A). Algumas intrusóes foram afetadas pela segunda fase deformacional (a mesma que gerou a superfície $S$ ), formando, assim, pequenos boudins e estruturas sigmoidais, ambos também associados a uma cinemática dextral (Fig. 4B).

$\mathrm{Na}$ análise petrográfica microscópica, as rochas do G1 apresentam feiçóes típicas de rochas metamórficas. O metagranodiorito é constituído por K-feldspato (em destaque a microclina), quartzo, plagioclásio, biotita e hornblenda, tendo como minerais acessórios a titanita, os minerais opacos, a apatita e o zircão. Os cristais de feldspato e quartzo comumente apresentam extinção ondulante e contatos retos associados a junçôes tríplices. Outra característica importante é a presença de fitas de quartzo (ribbon) e textura granoblástica. 


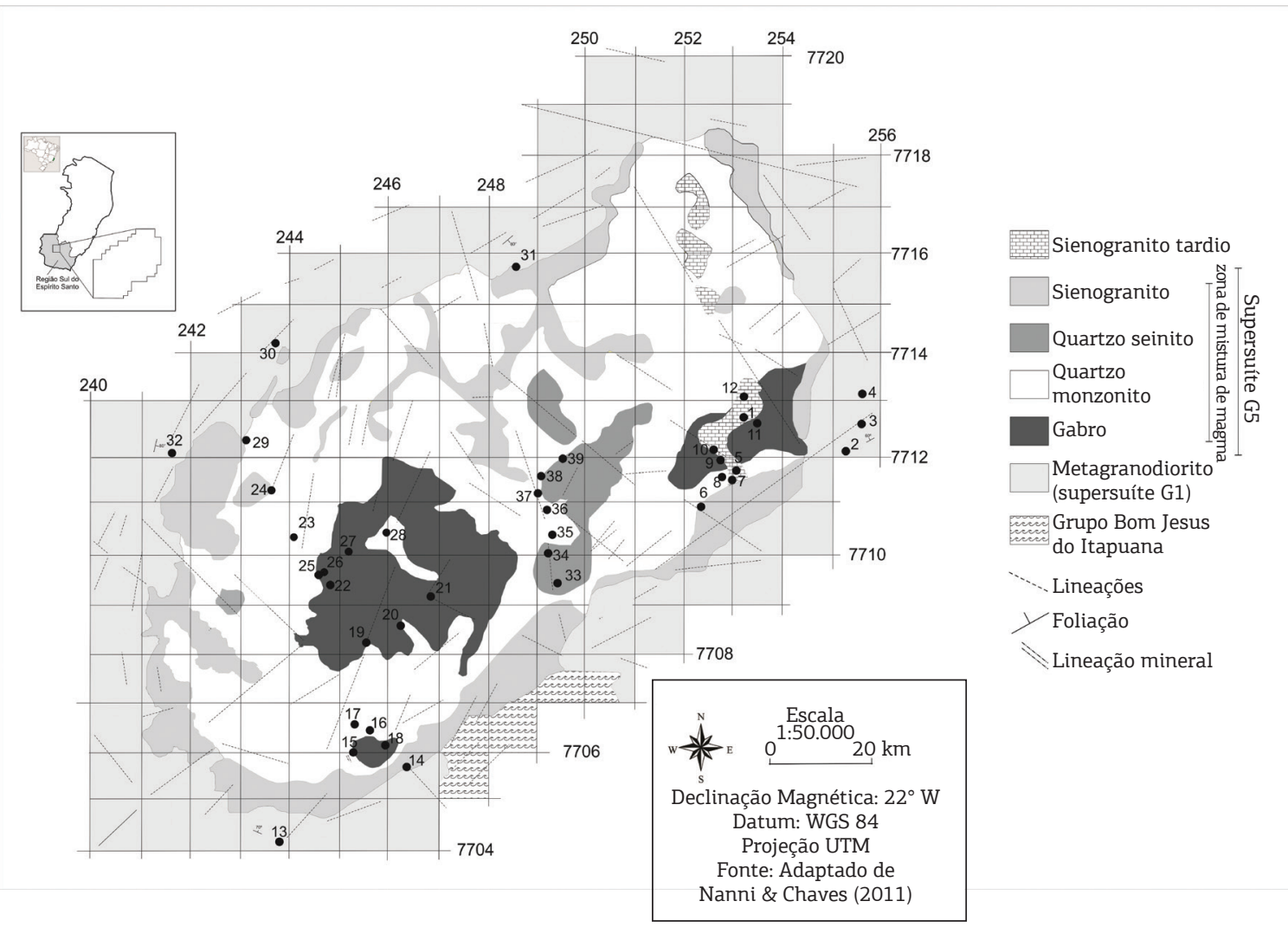

Figura 2. Mapa geológico do Maciço Santa Angélica e suas encaixantes.
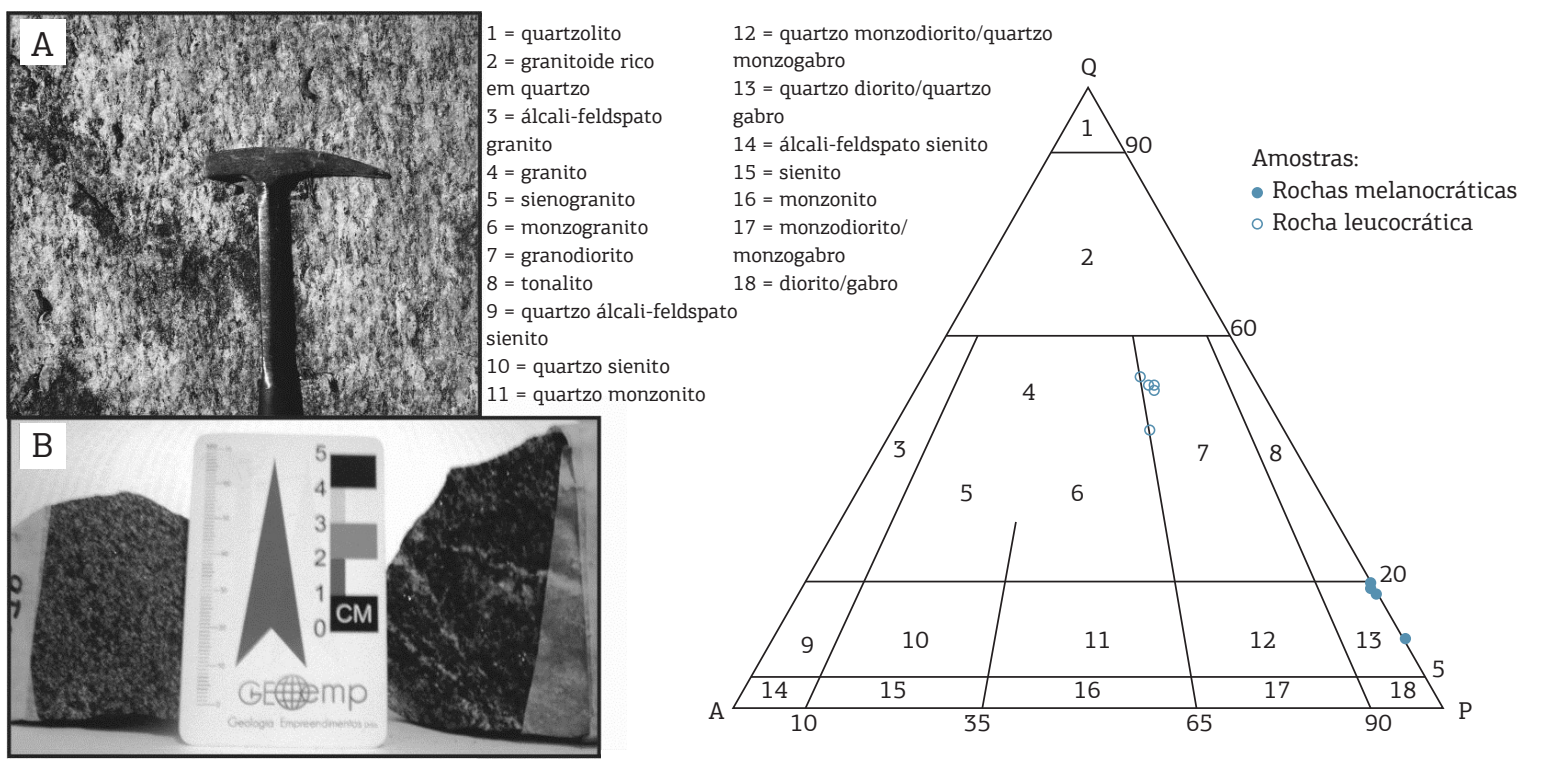

Figura 3. Aspectos petrográficos das rochas pertencentes à Supersuíte G1: (A) metagranodiorito (Ponto 3); (B) metaquartzo biotita hornblenda gabro (à esquerda fase mais velha e à direita fase tardia) (Ponto 4); (C) classificação petrográfica das amostras estudadas segundo o diagrama QAP (Streickeisen 1967). 


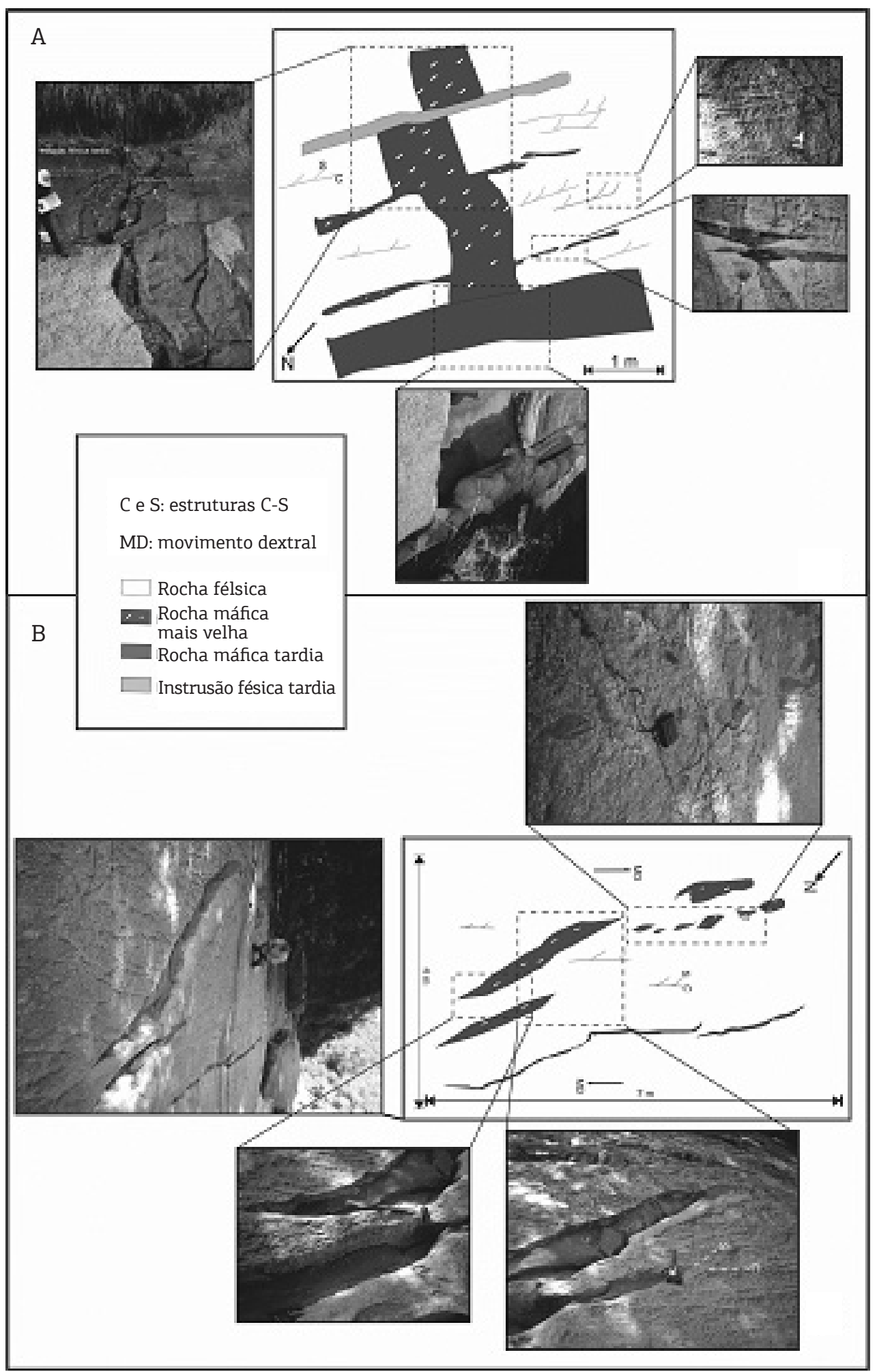

Figura 4. Aspectos deformacionais da Supersuíte G1: relação entre as estruturas S-C e as falhas transcorrentes (A), os sigmoides e os boudins gerados a partir das intrusões máficas (B). 
O metaquartzo biotita hornblenda gabro tem como minerais essenciais plagioclásio, biotita, hornblenda e quartzo, e como acessórios titanita, minerais opacos e apatita. Apresenta textura lepidoblástica e os cristais de quarto possuem extinção ondulante e textura de recristalização. Algumas das amostras desse litotipo apresentam porfiroclastos de quartzo e plagioclásio.

No CISA são encontrados na sua borda o sienogranito e o quartzo sienito (in situ e na forma de blocos rolados) separados dos dois núcleos de gabro por uma extensa zona de mistura de magmas (Fig. 5). O sienogranito é constituído por K-feldspato, quartzo, plagioclásio e biotita, tendo como minerais acessórios os minerais opacos, a allanita e a titanita. O quartzo sienito apresenta mineralogia semelhante ao litotipo anterior, porém possui hornblenda e não tem allanita. Já o gabro tem como minerais essenciais o plagioclásio, o clinopiroxênio, a biotita e o quartzo, e como acessórios os minerais opacos e a apatita.
No sienogranito foram encontrados enclaves de ortognaisses da Supersuíte G1, com tamanho entre 10 e $40 \mathrm{~cm}$ (Fig. 6). O contato entre eles ocorre de forma gradacional, sem nenhuma borda de reação que indicasse contraste de temperatura; por isso, esses enclaves são interpretados como restitos. Nessa mesma região os cristais de K-feldspato do sienogranito adquirem aspecto alongado e lenticular, semelhante àquele encontrado nos augen gnaisses. Tanto os cristais quanto os restitos se mostram orientados segundo trend NE/SW (o mesmo da foliação da encaixante).

O estudo petrográfico microscópico da amostra de sienogranito coletada no mesmo ponto descrito acima também revelou características deformacionais igualmente observadas no metagranodiorito, tais como: texturas granoblástica e lepidoblástica (Fig. 7A), grãos de quartzo poligonizados e associados a junçôes tríplices (Fig. 7C), além de fitas de quartzo (ribbon) (Fig. 7B).

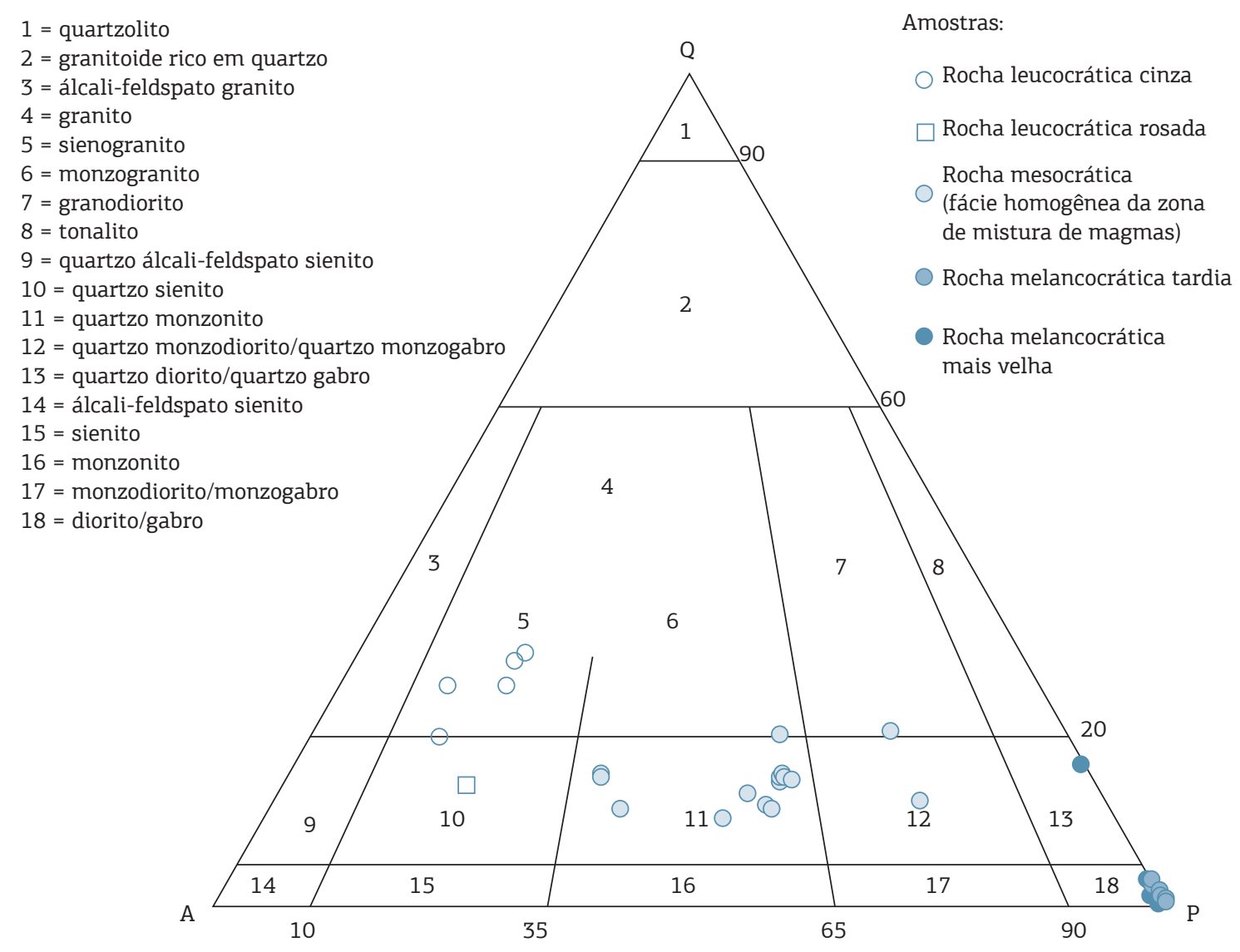

Figura 5. Classificação petrográfica das amostras analisadas do Maciço Santa Angélica segundo o diagrama QAP (Streickeisen 1967). 
Os registros de campo mostram que o gabro está associado a mais de um pulso magmático: o primeiro (e o predominante) apresenta granulação mais grossa e os mais novos possuem granulação fina (e por serem pontuais foram considerados como um único litotipo) (Fig. 8A). O gabro mais velho é constituído por plagioclásio, clinopiroxênio, biotita e quartzo, tendo como minerais acessórios os minerais opacos e a apatita (Fig. 8B). Já o gabro tardio apresenta textura porfirítica, com matriz de composição semelhante ao litotipo anterior e fenocristais de plagioclásio e clinopiroxênio (Fig. 8C).

As zonas de mistura de magma caracterizam-se por faixas de 5 a $500 \mathrm{~m}$ de extensão, constituídas por enclaves de diferentes composiçóes, desde os litotipos félsicos aos máficos aqui citados, todos pertencentes ao G5. Estas regiôes são divididas em duas fácies: uma de textura homogênea (possível magma mixing) e outra com textura heterogênea, denominada como magma mingling (Fig. 9).

O estudo petrográfico realizado com amostras da fase homogênea mostrou que sua assembleia mineral é constituída por K-feldspato, plagioclásio, biotita, quartzo, clinopiroxênio, sendo classificado como quartzo monzonito. Como minerais acessórios são encontrados minerais opacos, apatita e titanita.
Em ambas as fácies e também no gabro tardio é comum a presença de xenocristais de K-feldspato de até $3 \mathrm{~cm}$ de tamanho, com pequena borda de reação indicando que estes sejam oriundos de um magma ácido (associado ao sienogranito) (Figs. 10A e 10B). Na microscopia óptica, esses cristais apresentam fraturas que comumente são preenchidas por quartzo e plagioclásio bordejados ou não por mirmequita (Fig. 10D). Sua borda de reação é caracterizada por um aglomerado de pequenos gráos de plagioclásio contornados por lamelas de quartzo, formando, assim, uma espécie de mirmequita com 2,5 mm de largura (Fig. 10C).

A última unidade presente na área de estudo, representada por uma rocha leucocrática porfirítica tardia de cor cinza claro, foi classificada também como sienogranito (Figs. 11A e 11D). Sua matriz é constituída essencialmente por K-feldspato (em destaque a microclina), quartzo, plagioclásio, biotita e, em menor proporção, muscovita. Os minerais opacos, a titanita e a apatita correspondem aos minerais acessórios. Já os fenocristais são representados pelo K-feldspato, correspondendo a aproximadamente 3\% da rocha.

Esse litotipo se localiza na porção oeste do maciço e ocorre na forma de blocos rolados e in situ. Segundo os dados geocronológicos U-Pb em zircóes (Söllner

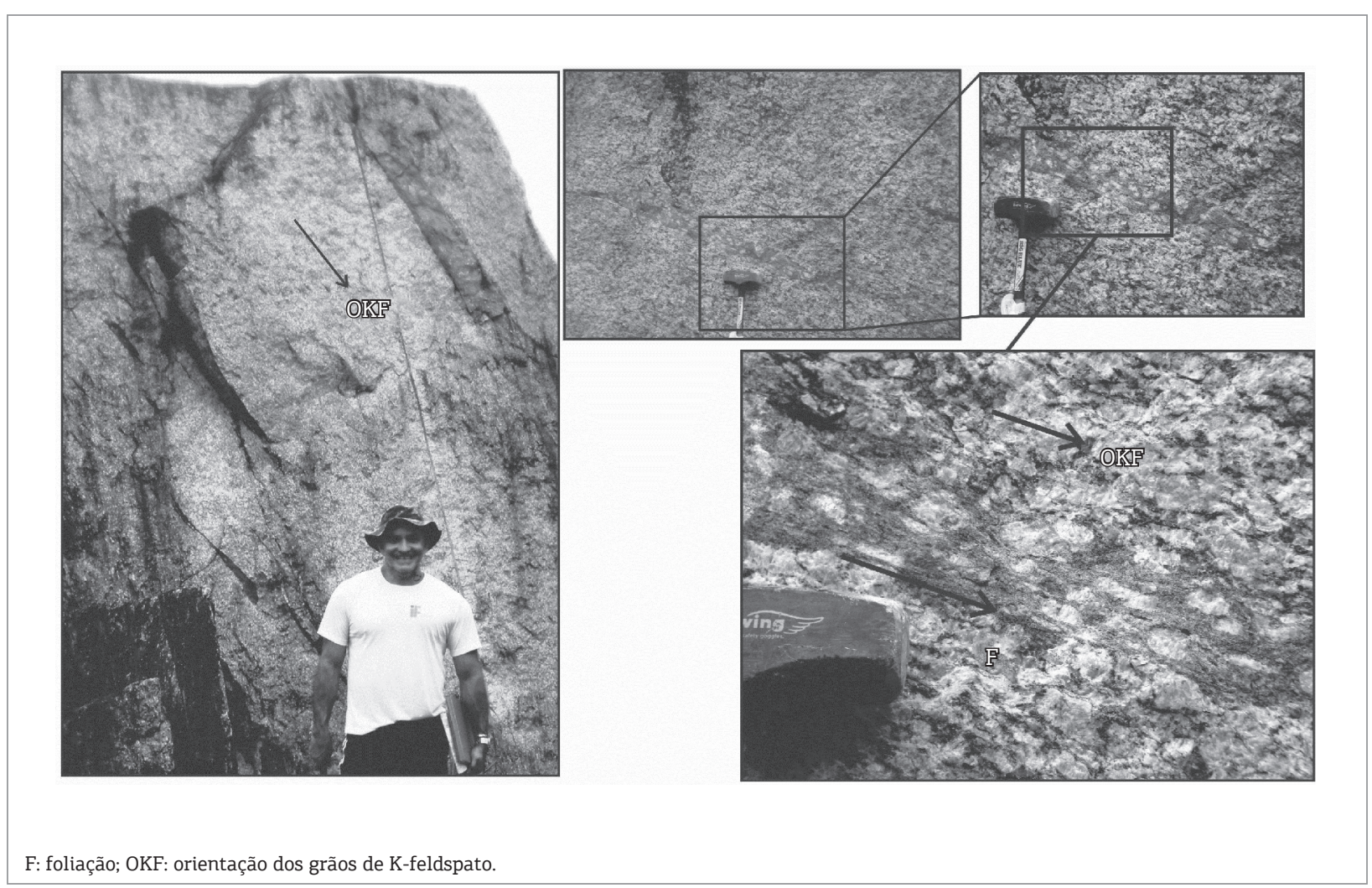

Figura 6. Relação entre a orientação dos grãos de K-feldspato, a foliação e a posição dos restitos (Supersuíte G1) (Ponto 15). 
et al. 2000), sua idade é de $492 \mathrm{Ma} \mathrm{(+/-} 15 \mathrm{Ma})$, período correspondente à fase final ou posterior à Supersuíte G5. Tal questão pode ser reafirmada a partir da observação de xenólitos representantes das Supersuítes G1 e G5 em seu interior (Fig. 11C). Pegmatitos também são registrados nesta unidade (Fig. 11B).

\section{Litogeoquímica e análise em microssonda}

O estudo litogeoquímico foi desenvolvido a partir da análise de 29 amostras e da interpretação dos seus resultados em diagramas magmáticos (Tabs. 1 e 2). Considerando as semelhanças observadas entre os litotipos durante as etapas anteriores de estudo, os mesmos foram agrupados da seguinte forma:
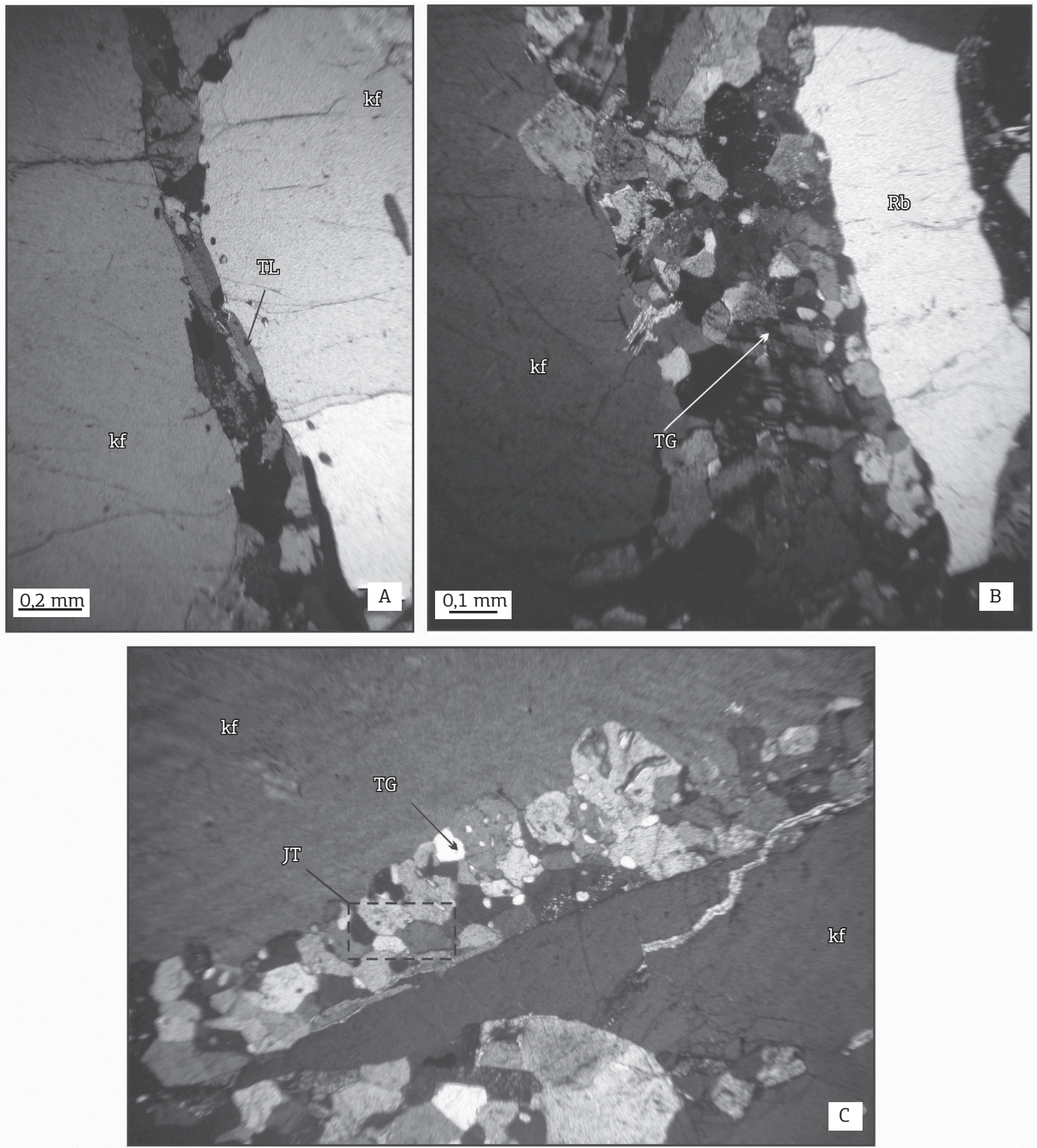

kf: K-feldspato; TL: textura lepidoblástica; TG: textura granoblástica; Rb: textura em fita (ribbon); JT: junções tríplices.

Figura 7. Feições deformacionais observadas em uma das amostras do sienogranito (amostra F5G15): (A) textura lepidoblástica; (B) textura granoblástica e fitas de quartzo (ribbon); (C) textura granoblástica e cristais com contatos tríplices. 

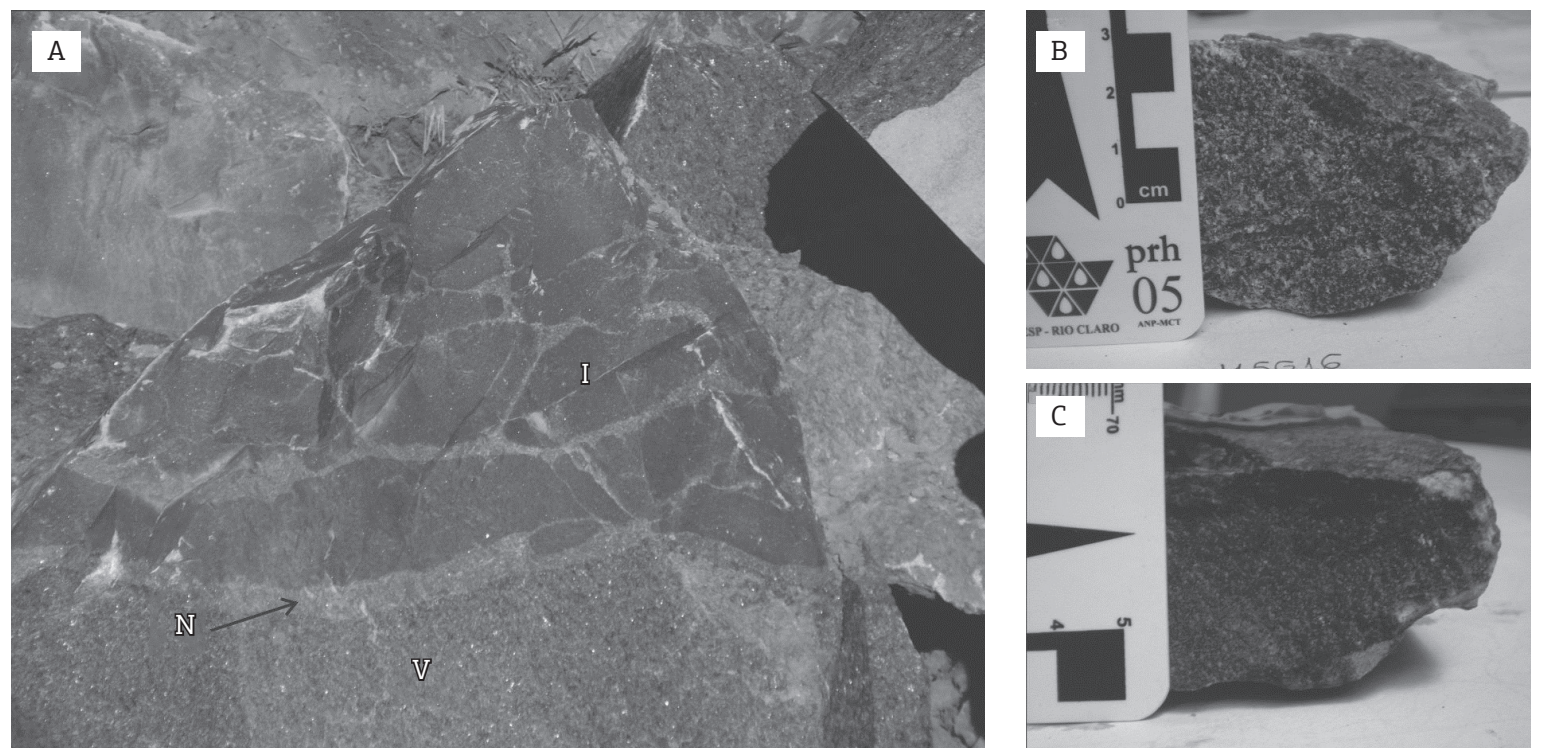

N: novo; I: intermediário; V: velho

Figura 8. Formas de ocorrência do gabro (Supersuíte G5): (A) os diferentes pulsos magmáticos; (B) gabro; (C) gabro tardio. A rocha mais velha foi denominada gabro, enquanto as demais fases representam o gabro tardio.
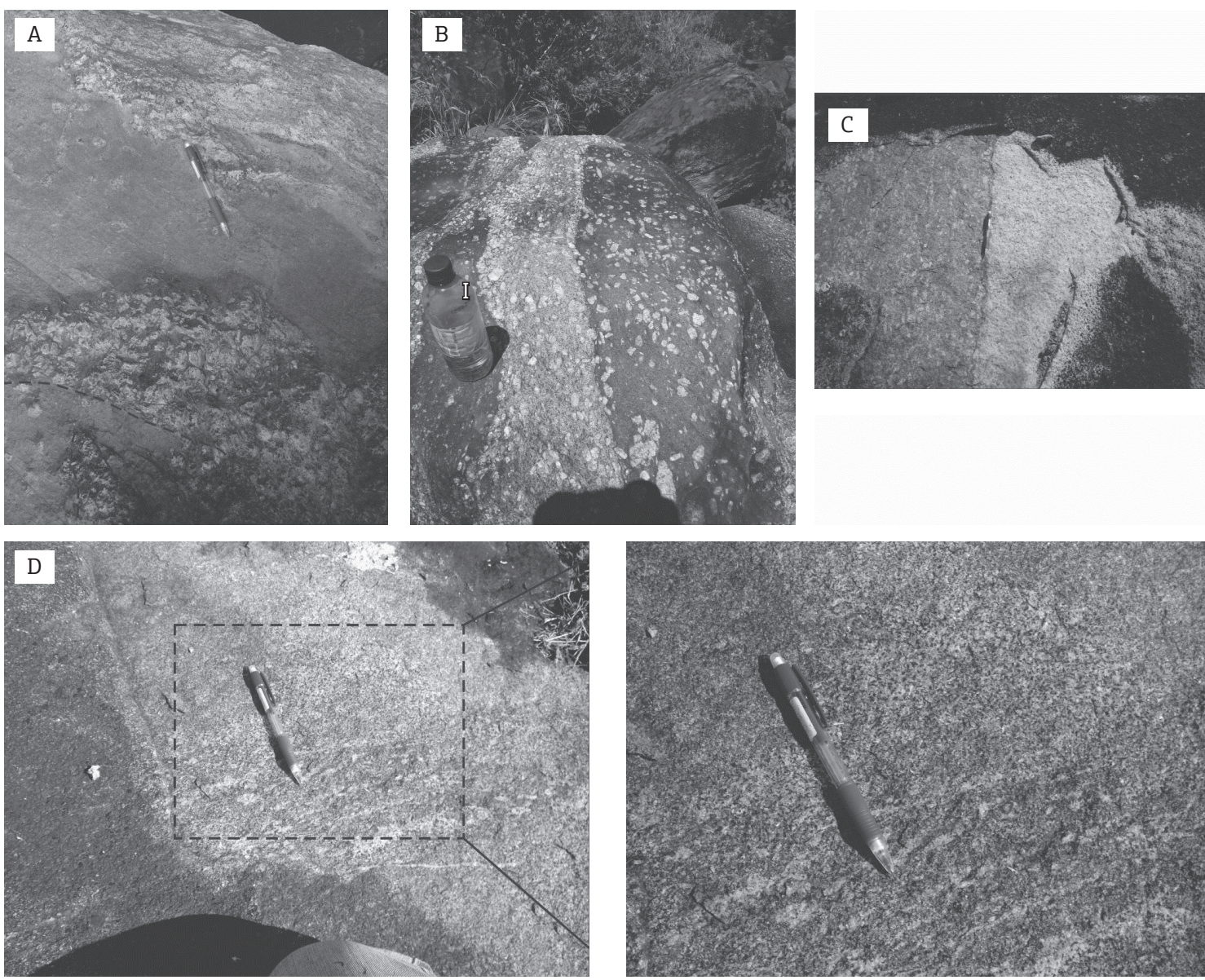

Figura 9. Zona de mistura de magmas: (A a C): zona do magma mingling; (D) região homogênea (possível magma mixing). 
- Supersuíte G1: metagranodiorito, metaquartzo biotita hornblenda gabro, metagranodiorito (enclave presente no sienogranito da Supersuíte G5), sienogranito (Supersuíte G5) e sienogranito tardio;

- Supersuíte G5: gabro, gabro tardio, quartzo monzonito e quartzo sienito.

A classificação química das rochas mostrou-se semelhante aos resultados obtidos na petrografia microscópica para ambas as Supersuítes (Fig. 12). A investigação das rochas pertencentes à Supersuíte G1 reafirmou a predominância de metagranodiorito na regiāo, conforme descrito pela literatura (Pedrosa-Soares et al. 2001, Martins et al. 2003).

Os diagramas de Harker $\left(\mathrm{SiO}_{2}\right.$ versus óxidos e elementos traços) (Fig. 13), analisados apenas para amostras da Supersuíte G5, indicaram uma correlação positiva para $\mathrm{Na}_{2} \mathrm{O}, \mathrm{K}_{2} \mathrm{O}, \mathrm{Th}, \mathrm{Rb}, \mathrm{Zr}, \mathrm{Nb}$ e Hf. Já o $\mathrm{Al}_{2} \mathrm{O}_{3}$ está disperso, enquanto os demais óxidos e elementos menores apresentam uma correlação negativa. Em todos esses diagramas são notados trends de cogeneticidade entre as amostras.

Quanto às séries magmáticas, as amostras do G1 dividem-se em alcalina transicional ou saturada em sílica (rochas máficas) e subalcalina cálcio-alcalina (rochas félsicas) (Figs. 14A e 14B). Já a Supersuíte G5 classifica-se como alcalina (Fig. 15A).

A análise da alumina-saturação indicou que as rochas leucocráticas do G1 em questão são metaluminosas a peraluminosas (Fig. 14B). E os resultados para os litotipos leucocráticos e mesocráticos do G5 indicam um caráter metaluminoso (Fig. 14B).

Os diagramas dos ETR e incompatíveis mostram padróes semelhantes entre as amostras agrupadas na Supersuíte G1
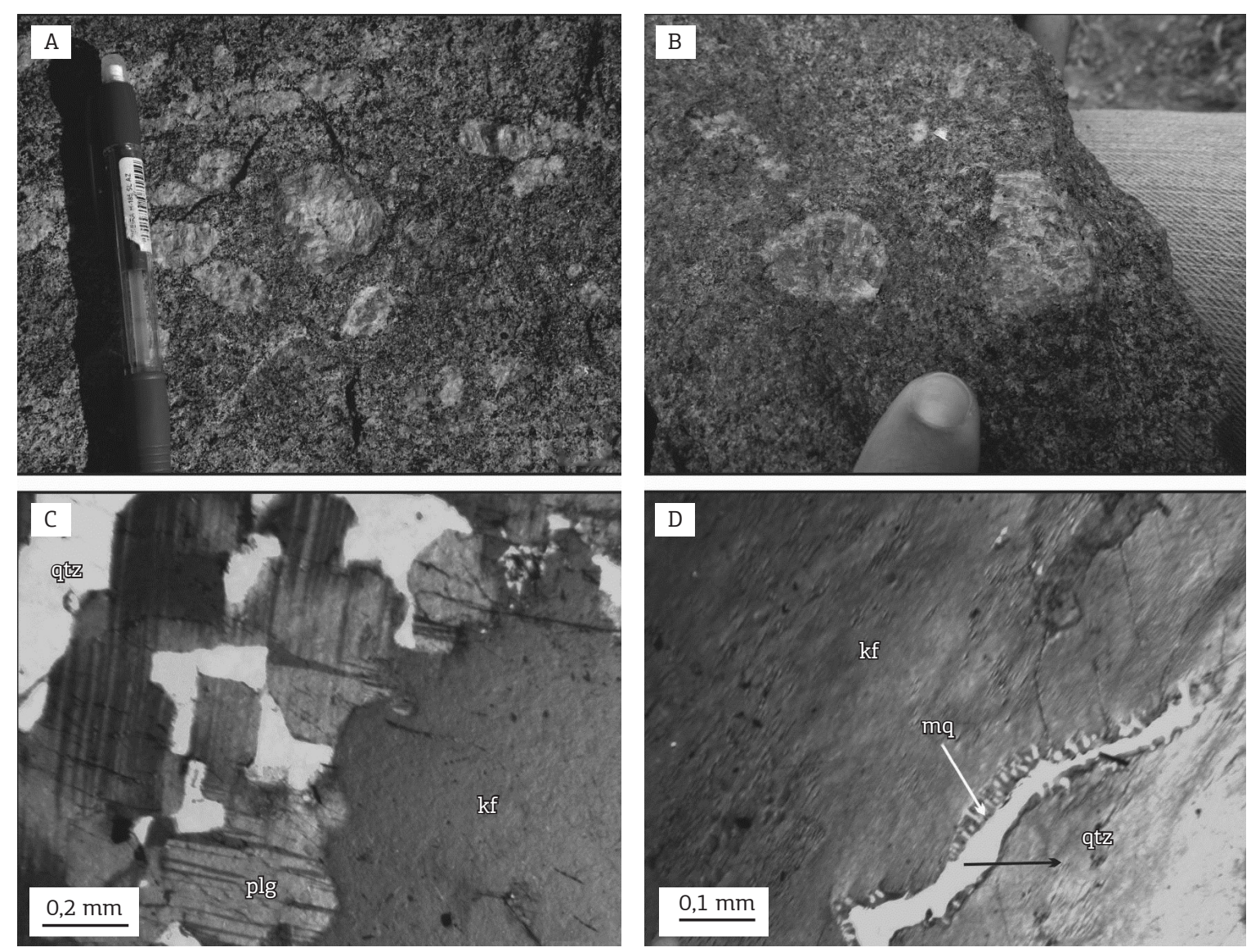

kf: K-feldspato; plg: plagioclásio; qtz: quartzo; mq: mirmequita.

Figura 10. Xenocristais presentes na fácies homogênea da zona de mistura de magmas (A) (Ponto 23) e no gabro tardio (B) (Ponto 22). Na microscopia óptica da amostra de quartzo monzonito (amostra D5MIX23B), a análise do xenocristal de K-feldspato indicou: (C) borda de reação do xenocristal formada por mirmequita; (D) fraturas preenchidas por quartzo bordejado por mirmequita. 
(Figs. 14D e 14E). Entretanto, percebe-se que houve um maior enriquecimento nestes elementos nas rochas melanocráticas. São identificadas anomalias negativas em Sr, P e Ti, além de haver um empobrecimento em large-ion lithophile element (LILE) na maioria das análises.

A análise dos ETR e elementos incompatíveis para a Supersuíte G5 indicou padróes semelhantes para todas as amostras e um menor enriquecimento em tais elementos nas melanocráticas que nas leucocráticas (Figs. 15C e 15D). No diagrama dos ETR também há uma anomalia em Eu mais pronunciada nos termos mais evoluídos da série. Já nos incompatíveis percebe-se um empobrecimento em LILE, além de anomalia negativa em $\mathrm{Nb}, \mathrm{Sr}, \mathrm{P}$ e Ti.
Os diagramas de classificação tectônica das amostras do G1 sugerem que os litotipos leucocráticos mais novos são tardi-orogênicos, enquanto os demais (metagranodiorito e enclave similar) estão associados aos estágios pré a sincolisional (Fig. 14F), assim como previsto pela literatura. Na análise segundo Pearce et al. (1984), que considera Rb versus $\mathrm{Y}+\mathrm{Nb}$, os metagranodioritos são classificados como granitos de arco magmático (Fig. 14G), reafirmando a questão anterior.

Os resultados quanto aos ambientes tectônicos das rochas pertencentes à Supersuíte G5 também confirmam estudos anteriores: os litotipos mesocráticos e leucocráticos estão associados ao soerguimento pós-orogênico/tardi-orogênico (Figs. 15E e 15F).

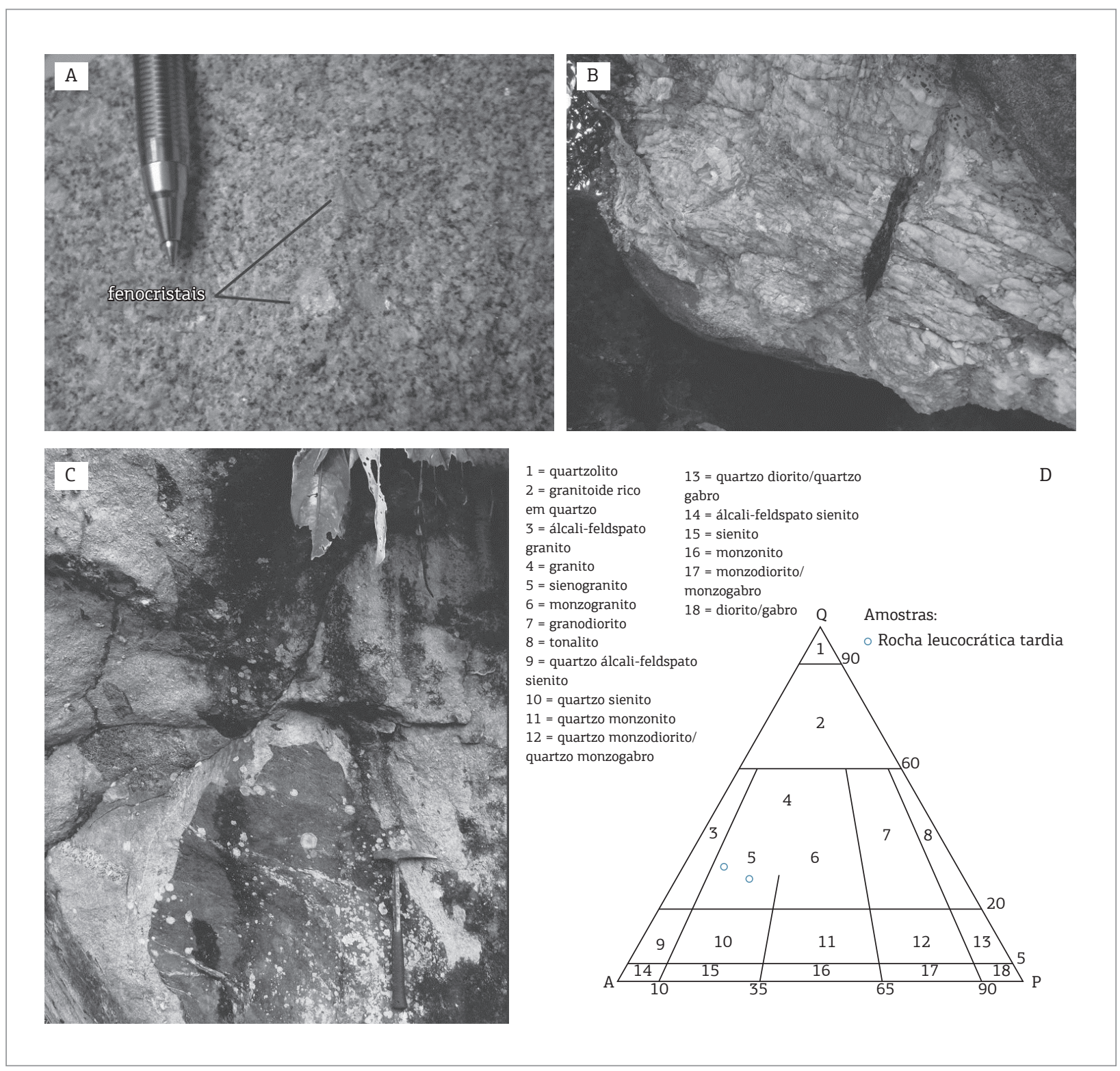

Figura 11. Aspectos gerais do sienogranito tardio: (A) sienogranito tardio (Ponto 1); (B) fase pegmatítica associada (Ponto 5); (C) xenólitos representantes das Supersuítes G1 e G5 (Ponto 5); (D) classificação petrográfica segundo o diagrama QAP (Streickeisen 1967). 
Tabela 1. Resultados das análises litogeoquímicas das amostras correspondentes à Supersuíte G1. As amostras iniciadas com a letra $\mathrm{M}$ são máficas, as com $\mathrm{F}$ correspondem às félsicas, EGN corresponde ao enclave de sienogranito da Supersuíte G5.

\begin{tabular}{|c|c|c|c|c|c|c|c|c|c|c|}
\hline & M1N4A & M1V4A & M12A & F12 & F14 & F114 & EGN15B & F5G24 & F5F1 & F5F10 \\
\hline $\mathrm{SiO}_{2}$ & 50,69 & 48,68 & 51,15 & 67,67 & 68,12 & 70,14 & 72,28 & 72,04 & 68,6 & 67,86 \\
\hline $\mathrm{TiO}_{2}$ & 2,14 & 2,12 & 2,86 & 0,5 & 0,44 & 0,38 & 0,27 & 0,27 & 0,8 & 0,78 \\
\hline $\mathrm{Al}_{2} \mathrm{O}_{3}$ & 16,53 & 14,56 & 15,69 & 15,86 & 15,97 & 14,61 & 13,33 & 13,78 & 15,14 & 15,28 \\
\hline FeOT & 10,67 & 11,48 & 12,17 & 3,93 & 3,47 & 3,23 & 2,41 & 2 & 3,91 & 4 \\
\hline $\mathrm{MnO}$ & 0,19 & 0,23 & 0,18 & 0,05 & 0,07 & 0,07 & 0,03 & 0,04 & 0,03 & 0,03 \\
\hline $\mathrm{MgO}$ & 4,85 & 8,31 & 3,96 & 0,71 & 0,78 & 0,58 & 0,36 & 0,21 & 0,79 & 0,77 \\
\hline $\mathrm{CaO}$ & 6,66 & 7,44 & 6,4 & 3,58 & 2,35 & 2,42 & 1,46 & 0,94 & 1,96 & 1,95 \\
\hline $\mathrm{Na}_{2} \mathrm{O}$ & 3,25 & 2,6 & 3,48 & 2,99 & 3,57 & 3,2 & 3,38 & 3,29 & 3,02 & 3,21 \\
\hline $\mathrm{K}_{2} \mathrm{O}$ & 4,44 & 3,95 & 3,57 & 3,71 & 5,49 & 3,44 & 4,06 & 6,06 & 5,55 & 5,59 \\
\hline $\mathrm{P}_{2} \mathrm{O} 5$ & 1,15 & 1,06 & 1,66 & 0,1 & 0,12 & 0,09 & 0,06 & 0,04 & 0,17 & 0,17 \\
\hline LOI & 0,47 & 0,31 & 0,09 & 0,22 & 0,13 & 0,94 & 0,6 & 0,15 & 0,65 & 0,38 \\
\hline Sum & 101,07 & 100,79 & 101,23 & 99,32 & 100,53 & 99,13 & 98,24 & 98,82 & 100,66 & 100,04 \\
\hline V & 155 & 194 & 236 & 50 & 45 & 48 & 52 & 3 & 28 & 30 \\
\hline Co & 25 & 36,4 & 23,9 & 1,3 & 5,5 & 26,5 & 90,4 & 1,8 & 15,7 & 25,3 \\
\hline $\mathrm{Ni}$ & 42 & 168 & 37 & 5 & 17 & 5 & 8 & 8 & 7 & 5 \\
\hline $\mathrm{Cu}$ & 26 & 23 & 23 & 9 & 8 & 7 & 29 & 10 & 11 & 10 \\
\hline Zn & 129 & 153 & 165 & 41 & 52 & 44 & 269 & 27 & 68 & 67 \\
\hline $\mathrm{Ga}$ & 20,1 & 18,3 & 24 & 19,7 & 16 & 17,7 & 18,5 & 16,3 & 23 & 24,3 \\
\hline Cs & 1,05 & 2,63 & 0,77 & 0,44 & 1,57 & 1,33 & 0,26 & 0,37 & 0,67 & 0,78 \\
\hline $\mathrm{Rb}$ & 92,9 & 111,2 & 80,9 & 63,9 & 104,9 & 91,9 & 98,7 & 123,1 & 185,7 & 198,8 \\
\hline $\mathrm{Ba}$ & 3300 & 2532 & 3059 & 2757 & 2478 & 1775 & 1336 & 1216 & 1708 & 1657 \\
\hline Th & 5,1 & 5,2 & 8 & 4,7 & 5,4 & 3,6 & 2,5 & 9 & 26,9 & 30,4 \\
\hline $\mathrm{U}$ & 1,03 & 1,76 & 1,95 & 0,66 & 4,13 & 0,88 & 0,92 & 1,99 & 1,68 & 2,12 \\
\hline $\mathrm{Nb}$ & 36 & 51 & 74 & 11 & 15 & 10 & 10 & 20 & 10 & 16 \\
\hline $\mathrm{Ta}$ & 2,4 & 2,48 & 3,73 & 0,6 & 1,21 & 0,59 & 0,94 & 1,21 & 0,27 & 0,5 \\
\hline $\mathrm{La}$ & 144,3 & 112,9 & 172,9 & 80 & 75,6 & 57,7 & 47,5 & 150,5 & 139,7 & 131,4 \\
\hline $\mathrm{Ce}$ & 246,3 & 192,4 & 311,5 & 131,1 & 129,3 & 94,7 & 59 & 231,6 & 229,2 & 218,9 \\
\hline $\operatorname{Pr}$ & 29,56 & 22,63 & 37,63 & 14,88 & 14,26 & 10,45 & 6,37 & 21,88 & 23,38 & 23,93 \\
\hline $\mathrm{Sr}$ & 1539 & 1028 & 1425 & 578 & 499 & 305 & 371 & 211 & 293 & 288 \\
\hline $\mathrm{Nd}$ & 108,9 & 89,3 & 145 & 53,1 & 51,7 & 38,8 & 20,5 & 63,4 & 76,5 & 78 \\
\hline $\mathrm{Zr}$ & 377 & 381 & 499 & 298 & 219 & 225 & 180 & 284 & 567 & 595 \\
\hline $\mathrm{Hf}$ & 5,1 & 6,16 & 9,12 & 4,59 & 4,46 & 3,87 & 3,18 & 5,39 & 8,97 & 8,47 \\
\hline $\mathrm{Sm}$ & 17,4 & 14,6 & 21,1 & 6,8 & 8,7 & 5,7 & 3,9 & 8,5 & 9,4 & 10,1 \\
\hline
\end{tabular}


Tabela 1. Continuação.

\begin{tabular}{l|c|c|c|c|c|c|c|c|c|c}
\hline & M1N4A & M1V4A & M12A & F12 & F14 & F114 & EGN15B & F5G24 & F5F1 & F5F10 \\
\hline $\mathrm{Eu}$ & 3,98 & 3,83 & 5,18 & 1,99 & 1,85 & 1,4 & 1,3 & 1,68 & 1,21 & 1,27 \\
\hline $\mathrm{Gd}$ & 11,37 & 10,18 & 15,4 & 4,67 & 7,55 & 4,36 & 2,57 & 4,29 & 4,75 & 6,14 \\
\hline $\mathrm{Tb}$ & 1,28 & 1,32 & 1,84 & 0,54 & 0,96 & 0,58 & 0,29 & 0,66 & 0,55 & 0,74 \\
\hline $\mathrm{Dy}$ & 5,95 & 5,7 & 8,19 & 2,66 & 5,5 & 2,9 & 1,43 & 2,54 & 2,26 & 2,88 \\
\hline $\mathrm{Y}$ & 23 & 23 & 29 & 14 & 23 & 19 & 10 & 12 & 12 & 15 \\
\hline $\mathrm{Ho}$ & 1,09 & 1,05 & 1,39 & 0,52 & 0,92 & 0,58 & 0,24 & 0,5 & 0,34 & 0,44 \\
\hline $\mathrm{Er}$ & 2,89 & 2,87 & 3,34 & 1,72 & 2,75 & 1,99 & 0,75 & 1,55 & 0,71 & 1,06 \\
\hline $\mathrm{Tm}$ & 0,38 & 0,43 & 0,43 & 0,15 & 0,37 & 0,24 & 0,06 & 0,22 & 0,06 & 0,09 \\
\hline $\mathrm{Yb}$ & 2,2 & 1,6 & 2,1 & 1,4 & 1,8 & 2 & 0,6 & 1,2 & 0,6 & 0,6 \\
\hline $\mathrm{Lu}$ & 0,32 & 0,27 & 0,3 & 0,25 & 0,29 & 0,36 & 0,2 & 0,14 & 0,08 & 0,13 \\
\hline $\mathrm{K}$ & 36859 & 32791 & 29636 & 30799 & 45575 & 28557 & 33704 & 50307 & 46073 & 46405 \\
\hline $\mathrm{Ti}$ & 12827 & 12707 & 17143 & 2997 & 2637 & 2278 & 1618 & 1618 & 4795 & 4675 \\
\hline $\mathrm{P}$ & 5018 & 4626 & 7244 & 436 & 524 & 393 & 262 & 175 & 742 & 742 \\
\hline $\mathrm{FeO}$ & 9,07 & 9,76 & 10,3 & 3,34 & 2,95 & 2,75 & 2,05 & 1,70 & 3,32 & 3,40 \\
\hline $\mathrm{Fe} \mathrm{O}_{3}$ & 1,60 & 1,72 & 1,83 & 0,59 & 0,52 & 0,48 & 0,36 & 0,30 & 0,59 & 0,60 \\
\hline
\end{tabular}

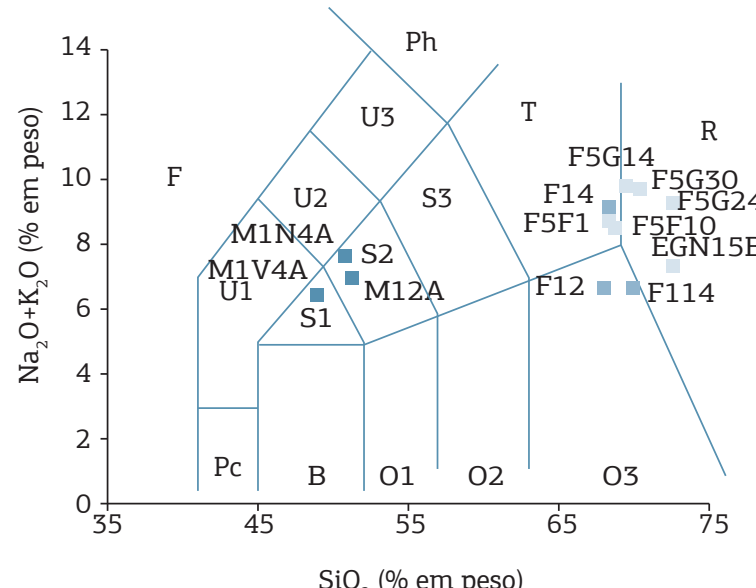

$\mathrm{SiO}_{2}$ (\% em peso)

Suíte G1:

Metaquartzo biotita

hornblenda gabro

Metagranodiorito

Sienogranito (Suite G5)

(enclave da suíte G5)

Sienogranito tardio

*Adaptada para classificação de rochas plutônicas.
Suíte G5

Quartzo monzonito

Gabro tardio

Gabro

Quartzo sienito

The

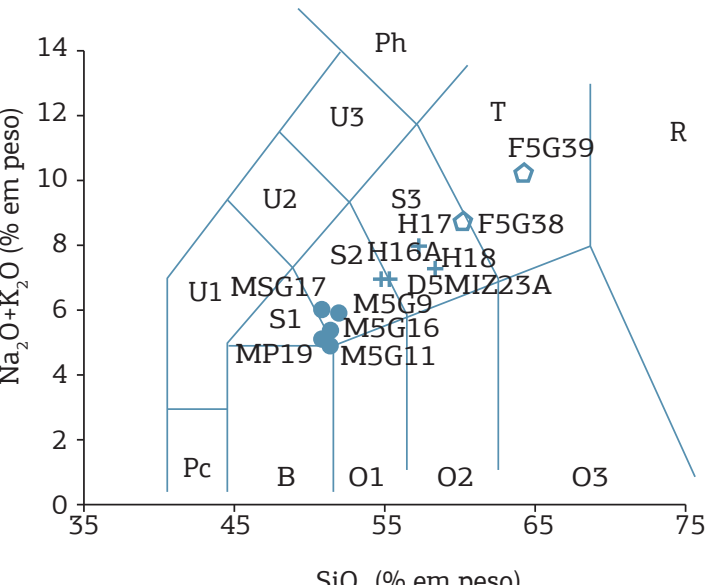

Suíte foifítica

Pf - picrofoiditos

F - foiditos

Suíte alcalina

Pc - picro basalto

U1 - basanito

U2 - fonotefrito

U3 - tefrito fonolítico

Suíte sílica

$\mathrm{R}$ - riolito
$\mathrm{SiO}_{2}$ (\% em peso)

$$
\begin{aligned}
& \text { Suíte transalcalina } \\
& \text { PC - picrobasalto } \\
& \text { B - basalto } \\
& \text { S1 traquibasalto } \\
& \text { S2 - traqui-andesito- } \\
& \text { basalto } \rightarrow \text { monzodiorito* } \\
& \text { S3 - traqui-andesito } \rightarrow \text { monzito* } \\
& \text { T - traquito } \rightarrow \text { sienito* } \\
& \text { Suíte subalcalina } \\
& \text { B - basalto } \\
& \text { O1 - andesito basáltico } \\
& \text { O2 - andesito } \\
& \text { O3 - dacito }
\end{aligned}
$$

Figura 12. Classificação química das amostras analisadas das Supersuítes G1 e G5 no diagrama TAS $\left(\mathrm{SiO}_{2}\right.$ versus $\mathrm{Na}_{2} \mathrm{O}+\mathrm{K}_{2} \mathrm{O}$ ), segundo Le Bas et al. (1986), adaptado por Middlemost (1991). 
A fim de compreender as possíveis reações químicas associadas à assimilação dos xenocristais de K-feldspato, foram realizadas análises em microssonda nas amostras de gabro tardio e de quartzo monzonito por meio de perfis traçados da borda para o centro do grão (Tab. 3 e Fig. 16). A variação composicional dos feldspatos em cada um dos perfis indica que houve uma variaçáo dos teores de anortita. Sendo assim, o teor de Ca é crescente da porção interna para a externa da borda de mirmequita, enquanto o teor de $\mathrm{Na}$ aumenta à medida que se aproxima do xenocristal (Zanon et al. 2012).

\section{DISCUSSÕES E CONCLUSÕES}

Os aspectos estruturais e petrográficos observados nos afloramentos pertencentes à Supersuíte G1 da encaixante ortoderivada do CISA indicam a ocorrência de, pelo menos,
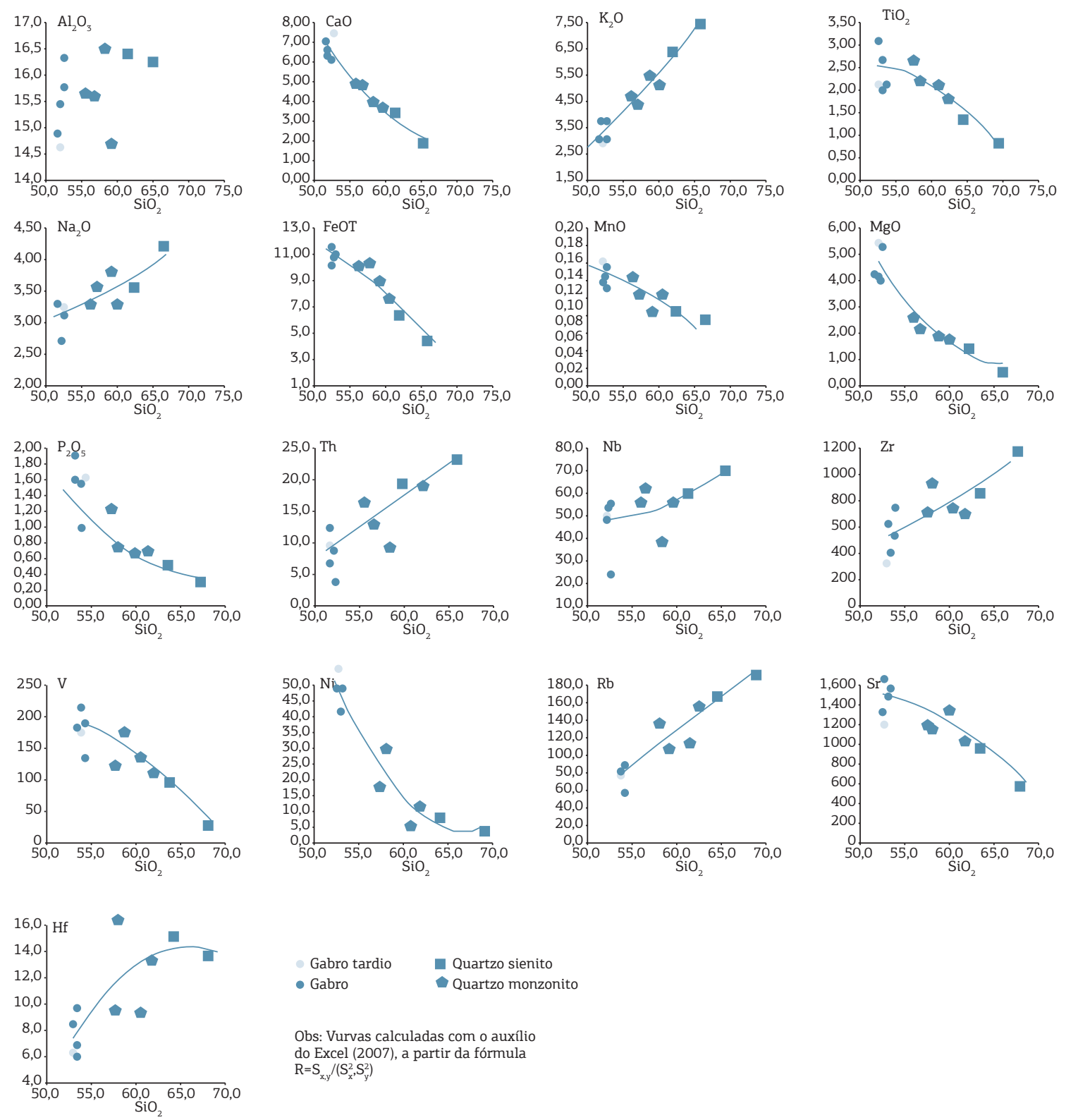

$$
\begin{aligned}
& \text { Gabro tardio Gabro } \\
& \text { Quartzo sienito } \\
& \text { Obs: Vurvas calculadas com o auxílio } \\
& \text { do Excel (2007), a partir da fórmula } \\
& \mathrm{R}=\mathrm{S}_{\mathrm{x}, \mathrm{y}} /\left(\mathrm{S}_{\mathrm{x}}^{2}, \mathrm{~S}_{\mathrm{y}}^{2}\right)
\end{aligned}
$$

Figura 13. Diagramas de Harker (1956) $\left(\mathrm{SiO}_{2}\right.$ versus óxidos - \% em peso - e elementos traços - ppm) de amostras pertencentes à Supersuíte G5. 


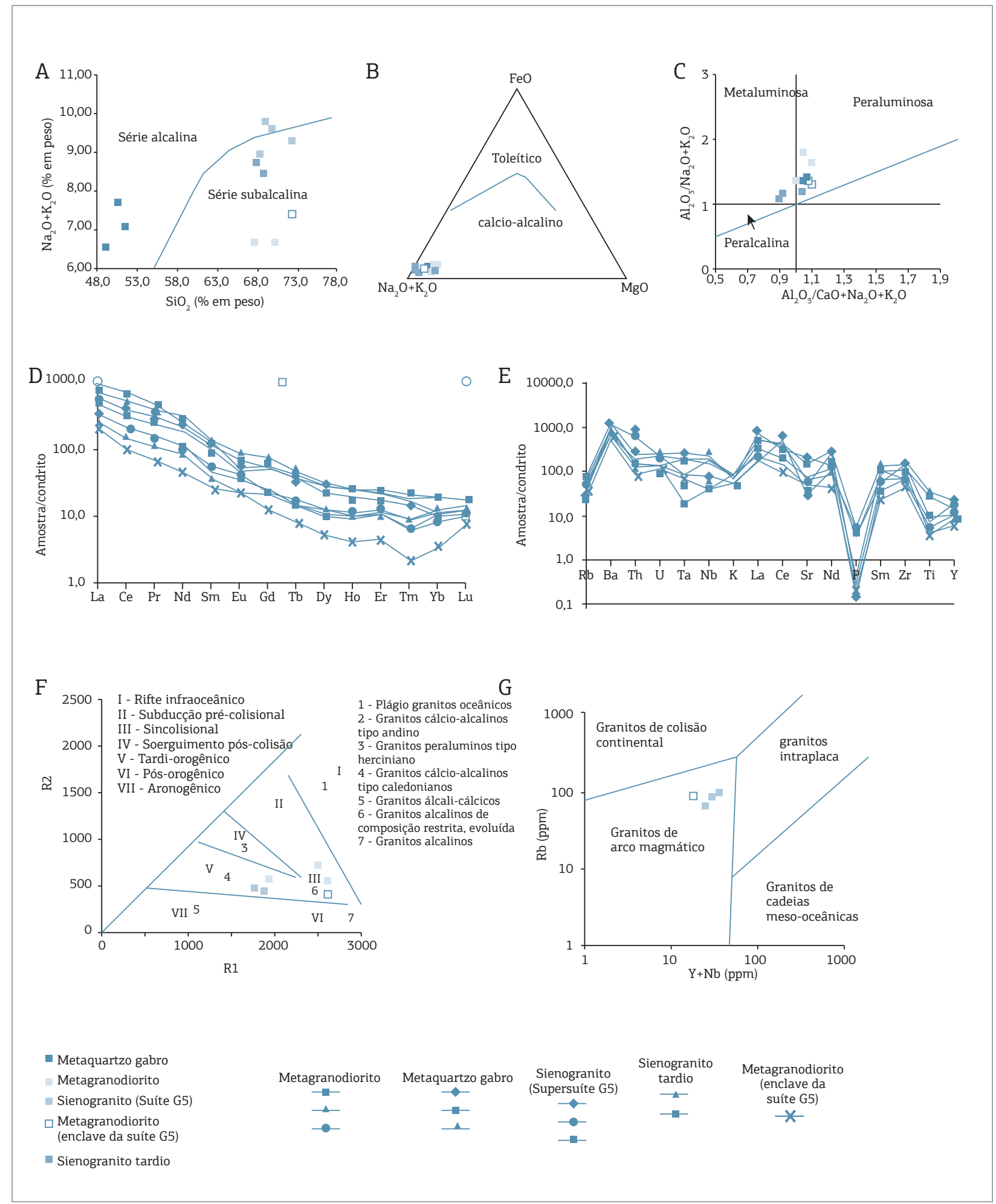

Figura 14. Diagramas litogeoquímicos da Supersuíte G1: (A) classificação das rochas quanto à série magmática segundo o diagrama TAS $\left(\mathrm{SiO}_{2}\right.$ versus $\left.\mathrm{Na}_{2} \mathrm{O}+\mathrm{K}_{2} \mathrm{O}\right)$ de Irvine \& Baragar (1971); (B) AFM de Irvine \& Baragar (1971) com as amostras leucocráticas (todos os óxidos estão em porcentagem de peso); (C) alumina-saturação de Shand (1949), adaptado por Maniar \& Piccoli (1984), com as amostras leucocráticas (todos os óxidos estão em proporções molares); (D) elementos terras raras com normalização, segundo Sun \& Mc Donough (1989); (E) elementos incompatíveis com normalização, segundo Sun \& Mc Donough (1989); (F) diagrama R1 x R2 para classificação das rochas leucocráticas quanto ao ambiente tectônico, segundo Batchelor \& Bowden (1985) (proporções calculadas em milications); (G) diagrama $\mathrm{Rb}$ versus $\mathrm{Y}+\mathrm{Nb}$ de Pearce et al. (1984) de classificação dos granitos quanto ao ambiente magmático. 
A

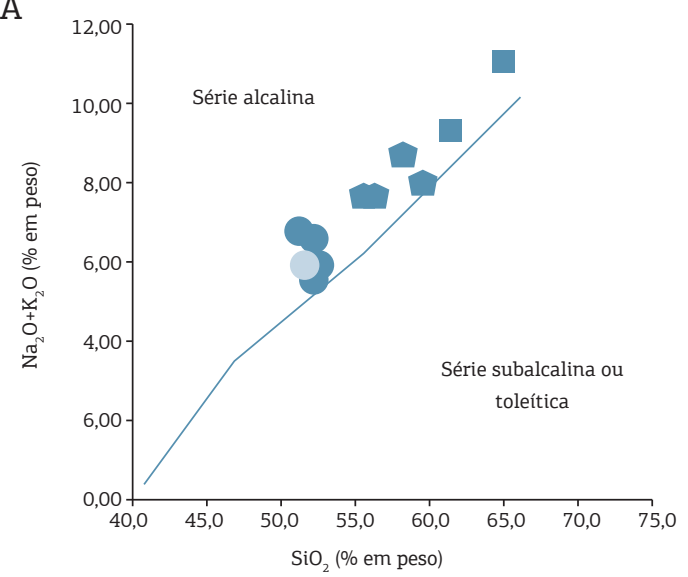

B

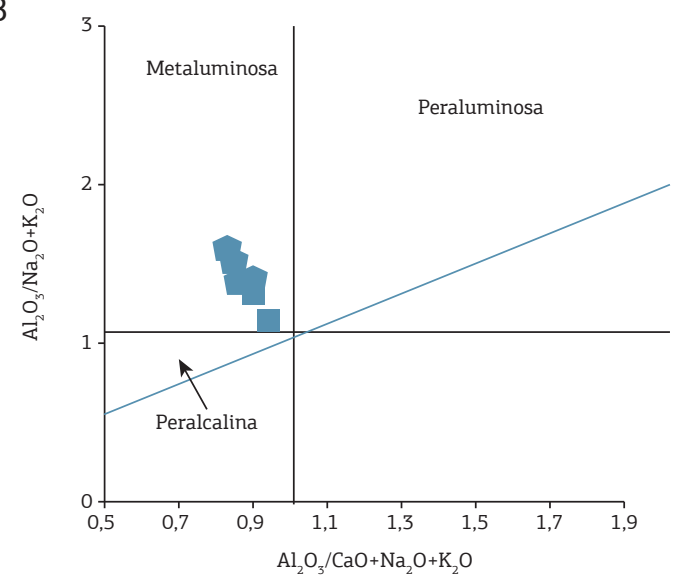

D

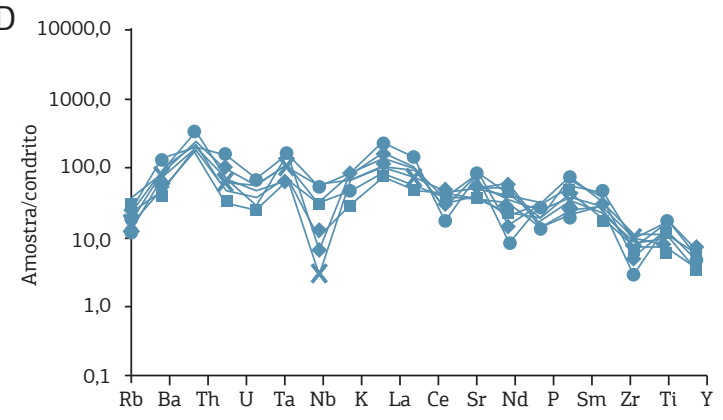

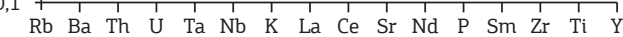
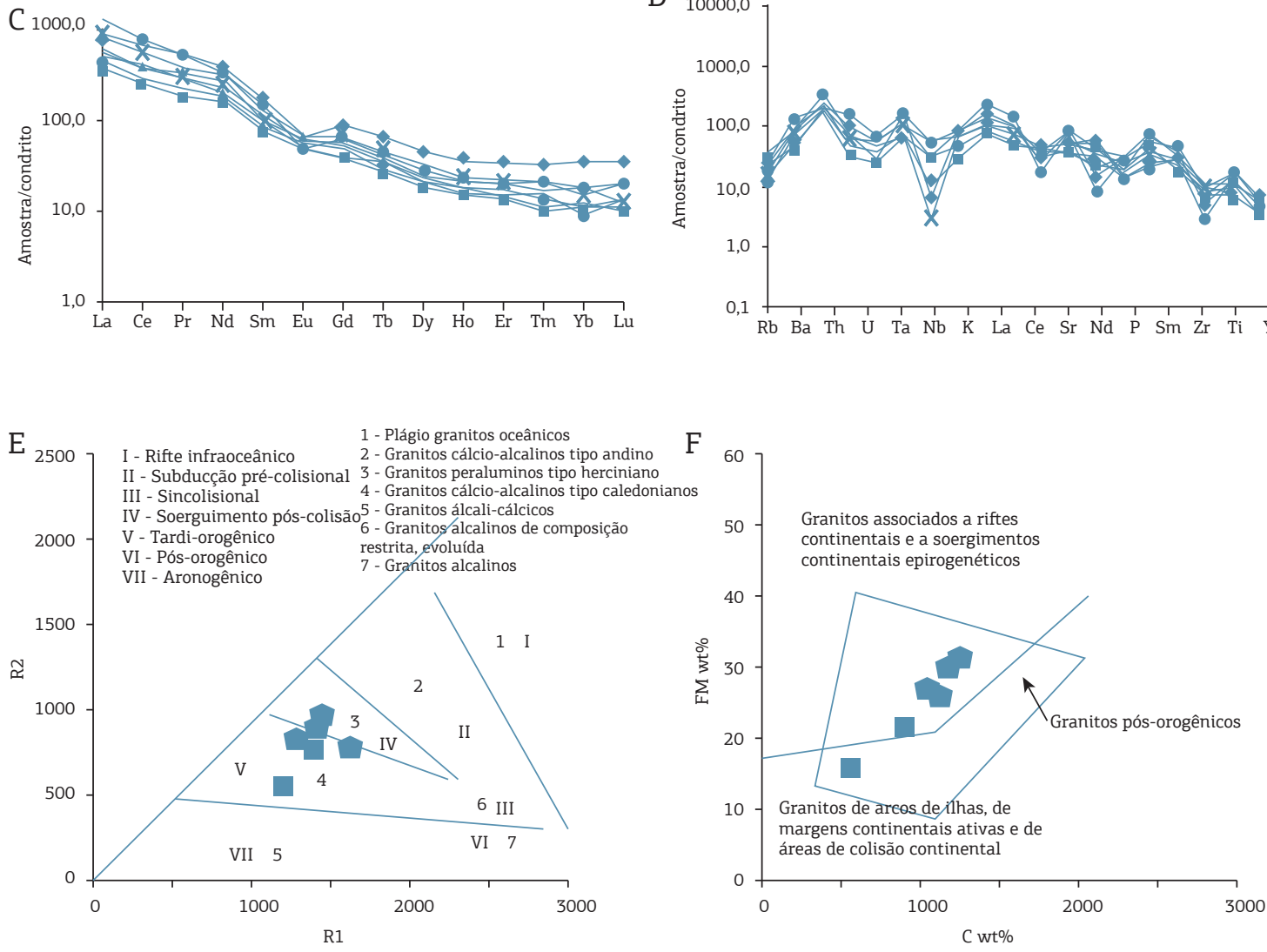

Gabro

Gabro tardio

Quartzo sienito

Quartzo monzonito
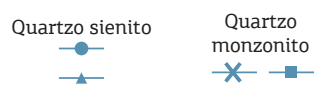

Gabro

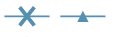

Gabro tardio

$\times \rightarrow-$

$\rightarrow$

Figura 15. Diagramas litogeoquímicos da Supersuíte G5: (A) classificação das rochas quanto à série magmática segundo o diagrama TAS $\left(\mathrm{SiO}_{2}\right.$ versus $\left.\mathrm{Na}_{2} \mathrm{O}+\mathrm{K}_{2} \mathrm{O}\right)$ de Irvine \& Baragar (1971); (B) alumina-saturação de Shand (1949), adaptada por Maniar \& Piccoli (1984), com as amostras leucocráticas (todos os óxidos estão em proporções molares); (C) elementos terras raras com normalização, segundo Sun \& Mc Donough (1989); (D) elementos incompatíveis com normalização, segundo Sun \& Mc Donough (1989); (E) diagrama R1 x R2 para classificação das rochas leucocráticas quanto ao ambiente tectônico, segundo Batchelor \& Bowden (1985) (proporções calculadas em milications); (F) diagrama para classificação FeO + MgO: CaO, segundo Maniar \& Picooli (1989), de granitos quanto ao ambiente tectônico das amostras félsicas e intermediárias. 
Marcela Lopes Zanon et al.

Tabela 2. Resultados das análises litogeoquímicas das amostras correspondentes à Supersuíte G5. As amostras iniciadas com a letra $\mathrm{M}$ são máficas, as com $\mathrm{F}$ correspondem às félsicas, as com D e H foram coletadas na zona de mistura de magmas.

\begin{tabular}{|c|c|c|c|c|c|c|c|c|c|c|c|}
\hline & D5MIX23A & M5G9 & M5G17 & F5G38 & H18 & H517 & H16A & M5G16 & F5G15 & M5G11 & MP19 \\
\hline $\mathrm{SiO}_{2}$ & 56,39 & 52,31 & 51,8 & 61,28 & 59,37 & 58,32 & 55,77 & 52,43 & 65,1 & & 51,96 \\
\hline $\mathrm{TiO}_{2}$ & 2,08 & 2,55 & 2,96 & 1,29 & 1,65 & 1,96 & 2,5 & 1,89 & 0,74 & 2,3 & 2 \\
\hline $\mathrm{Al}_{2} \mathrm{O}_{3}$ & 15,62 & 15,74 & 14,93 & 16,41 & 14,73 & 16,53 & 15,63 & 16,33 & 16,24 & 15,44 & 14,64 \\
\hline FeOT & 10,09 & 10,64 & 11,24 & 6,34 & 7,54 & 8,63 & 9,86 & 10,28 & 4,32 & 11,09 & 9,84 \\
\hline $\mathrm{MnO}$ & 0,11 & 0,14 & 0,15 & 0,09 & 0,11 & 0,09 & 0,13 & 0,12 & 0,08 & 0,13 & 0,15 \\
\hline $\mathrm{MgO}$ & 2,22 & 3,95 & 4,12 & 1,45 & 1,81 & 1,85 & 2,58 & 5,06 & 0,77 & 4,02 & 5,23 \\
\hline $\mathrm{CaO}$ & 4,85 & 6,13 & 7 & 3,38 & 3,8 & 4 & 4,98 & 7,41 & 1,95 & 6,58 & 6,32 \\
\hline $\mathrm{Na}_{2} \mathrm{O}$ & 3,52 & 3,04 & 3,21 & 3,48 & 3,2 & 3,71 & 3,23 & 3,05 & 4,11 & 2,69 & 3,16 \\
\hline $\mathrm{K}_{2} \mathrm{O}$ & 4,22 & 3,5 & 3,54 & 6,03 & 4,87 & 5,17 & 4,43 & 2,88 & 7,01 & 2,82 & 2,73 \\
\hline $\mathrm{P}_{2} \mathrm{O}_{5}$ & 0,65 & 1,38 & 1,72 & 0,42 & 0,59 & 0,58 & 1,11 & 0,86 & 0,21 & 1,45 & 0,9 \\
\hline LOI & 0,59 & 0,32 & 0,33 & 0,25 & 0,54 & 0,13 & 0,07 & 0,32 & 0,44 & 0,6 & 1,89 \\
\hline Sum & 100,4 & 99,71 & 101,01 & 100,43 & 98,21 & 101 & 100,3 & 100,65 & 100,98 & 99,08 & 98,83 \\
\hline $\log$ & $-0,203$ & $-0,0281$ & 0,0157 & $-0,449$ & $-0,3270$ & $-0,3463$ & $-0,187$ & 0,0967 & $-0,756$ & 0,0770 & 0,0306 \\
\hline V & 166 & 186 & 178 & 94 & 102 & 132 & 122 & 126 & 29 & 207 & 168 \\
\hline Co & 21,4 & 31,3 & 34,9 & 11,3 & 16,4 & 18,4 & 23,5 & 40 & 5,2 & 56,3 & 44,1 \\
\hline $\mathrm{Ni}$ & 23 & 34 & 39 & 7 & 9 & 5 & 14 & 41 & 3 & 39 & 44 \\
\hline $\mathrm{Cu}$ & 22 & 33 & 22 & 14 & 17 & 13 & 19 & 24 & 6 & 32 & 26 \\
\hline $\mathrm{Zn}$ & 155 & 140 & 145 & 107 & 110 & 108 & 153 & 99 & 76 & 116 & 108 \\
\hline $\mathrm{Ga}$ & 26,1 & 20,7 & 21,9 & 26,7 & 27,2 & 25,9 & 24 & 19,9 & 21,9 & 22,9 & 23,5 \\
\hline Cs & 0,49 & 0,75 & 0,58 & 0,65 & 0,62 & 0,88 & 0,71 & 0,37 & 0,46 & 0,56 & 0,3 \\
\hline $\mathrm{Rb}$ & 93,5 & 74,7 & 67,3 & 144,8 & 135,3 & 97,2 & 116,2 & 49,6 & 164,5 & 69,9 & 66,4 \\
\hline $\mathrm{Ba}$ & 2961 & 2364 & 2410 & 3342 & 2756 & 3721 & 2718 & 2476 & 2254 & 2204 & 1935 \\
\hline Th & 12,3 & 8,1 & 6,1 & 17,5 & 17,6 & 8,8 & 15,4 & 3,9 & 21,2 & 11,3 & 9 \\
\hline U & 1,09 & 1,86 & 1,78 & 2,49 & 2,3 & 1,65 & 2,2 & 0,91 & 2,42 & 1,7 & 1,35 \\
\hline $\mathrm{Nb}$ & 62 & 55 & 49 & 61 & 56 & 39 & 57 & 25 & 71 & 53 & 51 \\
\hline $\mathrm{Ta}$ & 1,62 & 0,15 & 0,43 & 0,37 & 1,59 & 1,76 & 3,46 & 0,6 & 3,04 & 0,76 & 1,82 \\
\hline $\mathrm{La}$ & 179,1 & 108,5 & 110,6 & 174,3 & 171,2 & 86,5 & 147,1 & 73,9 & 227,4 & 108,7 & 112,1 \\
\hline $\mathrm{Ce}$ & 320,1 & 179,3 & 203,5 & 291,6 & 284,5 & 142,4 & 257,9 & 125,4 & 377,1 & 191,8 & 189,9 \\
\hline $\operatorname{Pr}$ & 38,96 & 22,47 & 24,64 & 33,59 & 32,56 & 17,75 & 30,01 & 14,98 & 39,71 & 23,32 & 22,96 \\
\hline $\mathrm{Sr}$ & 992 & 1328 & 1145 & 834 & 889 & 1135 & 1017 & 1270 & 479 & 1408 & 1026 \\
\hline $\mathrm{Nd}$ & 152,3 & 86,1 & 98,3 & 121,6 & 119,9 & 70 & 114,4 & 62,1 & 134,3 & 90 & 88,8 \\
\hline $\mathrm{Zr}$ & 855 & 491 & 568 & 807 & 663 & 679 & 677 & 684 & 1100 & 363 & 306 \\
\hline $\mathrm{Hf}$ & 14,67 & 6,48 & 7,91 & 13,43 & 12,23 & 8,72 & 8,88 & 8,97 & 12,24 & 5,88 & 5,98 \\
\hline Sm & 22,5 & 13,5 & 14,2 & 16,5 & 18,6 & 10,7 & 17,2 & 9,7 & 19,6 & 13,6 & 13,5 \\
\hline $\mathrm{Eu}$ & 3,52 & 2,85 & 3,15 & 3,29 & 3,43 & 2,44 & 3,46 & 2,58 & 3,25 & 3,31 & 3,03 \\
\hline
\end{tabular}


Tabela 2. Continuação.

\begin{tabular}{l|c|c|c|c|c|c|c|c|c|c|c|c}
\hline & D5MIX23A & M5G9 & M5G17 & F5G38 & H18 & H517 & H16A & M5G16 & F5G15 & M5G11 & MP19 \\
\hline $\mathrm{Gd}$ & 15,86 & 8,66 & 10,82 & 11,05 & 12,72 & 7,56 & 12,15 & 7,24 & 11,64 & 9,38 & 10,41 \\
\hline $\mathrm{Tb}$ & 2,14 & 0,95 & 1,26 & 1,43 & 1,59 & 0,92 & 1,51 & 0,89 & 1,55 & 1,14 & 1,17 \\
\hline $\mathrm{Dy}$ & 10,15 & 5,12 & 5,8 & 6,24 & 6,98 & 4,36 & 6,94 & 4,28 & 6,86 & 4,87 & 5,41 \\
\hline $\mathrm{Y}$ & 32 & 29 & 31 & 29 & 32 & 20 & 36 & 22 & 27 & 22 & 27 \\
\hline $\mathrm{Ho}$ & 1,9 & 0,93 & 1,05 & 1,08 & 1,23 & 0,85 & 1,15 & 0,79 & 1,24 & 0,84 & 1,09 \\
\hline $\mathrm{Er}$ & 5,21 & 2,11 & 2,38 & 2,97 & 3,12 & 2,11 & 2,96 & 2,13 & 3,4 & 2,15 & 2,69 \\
\hline $\mathrm{Tm}$ & 0,76 & 0,24 & 0,32 & 0,37 & 0,42 & 0,26 & 0,39 & 0,23 & 0,5 & 0,24 & 0,36 \\
\hline $\mathrm{Yb}$ & 5,4 & 1,8 & 1,8 & 2,3 & 2,5 & 1,4 & 2,5 & 1,7 & 2,8 & 1,7 & 2,3 \\
\hline $\mathrm{Lu}$ & 0,84 & 0,24 & 0,3 & 0,33 & 0,4 & 0,28 & 0,32 & 0,31 & 0,29 & 0,24 & 0,45 \\
\hline $\mathrm{K}$ & 35032 & 29055 & 29387 & 50058 & 40428 & 42919 & 36776 & 23908 & 58193 & 23410 & 22663 \\
\hline $\mathrm{Ti}$ & 12467 & 15285 & 17742 & 7732 & 9890 & 11748 & 14985 & 11329 & 4436 & 13786 & 11988 \\
\hline $\mathrm{P}$ & 2836 & 6022 & 7506 & 1833 & 2575 & 2531 & 4844 & 3753 & 916 & 6328 & 3927 \\
\hline
\end{tabular}

duas fases deformacionais principais (D1 e D2), ambas sob condiçôes dúcteis. A análise de campo sugere que os corpos máficos maiores intrudiram anteriormente ao processo deformacional.

A D1 corresponde a fase de milonitização do metagranodiorito (geraçáo de C) e falhamentos das intrusóes maiores com movimento dextral. Os planos de falhas possibilitaram a entrada de novos corpos (máficos e félsicos) de pequena dimensão (vide Fig. 4).

A segunda fase deformacional (D2) resultou na formação de estruturas do tipo $S$ e dos sigmoides e boudins dos corpos máficos (principalmente os menores) com a mesma cinemática de D1. O fato de os enclaves observados nas intrusôes maiores apresentarem orientação similar à $S$ sugere que também foram afetados por D2.

A litogeoquímica e a petrografia microscópica de amostras pertencentes à Supersuíte G1 reafirmaram as características levantadas em estudos anteriores: a rocha mais abundante é o metagranodiorito, de caráter subalcalino (cálcio-alcalino) e peraluminoso (que, apesar de não ser o mais usual, é registrado na literatura), de ambiente pré-colisional a sincolisional de arco magmático.

Os diagramas de TAS (Le Bas et al. 1986 adaptado por Middlemost 1991), $\mathrm{SiO}_{2}$ versus $\mathrm{Zr} / \mathrm{TiO}_{2}$ (Winchester \& Floyd 1977), AFM (Irvine \& Baragar 1971) e alumina-saturação (Shand 1949 adaptado por Maniar \& Piccoli 1984) mostram uma relação entre o metagranodiorito e ambos os sienogranitos localizados no CISA. Quanto aos ETR e elementos incompatíveis, os padróes também apresentam forte semelhança. Tais questóes, somadas às características petrográficas observadas principalmente no litotipo do G5 (vide
Figs. 6 e 7), indicam que as rochas mais novas são produtos da fusão parcial dessa encaixante.

Com exceção do sienogranito, os demais litotipos do G5 apresentam características petrográficas e geoquímicas que possibilitam correlacioná-los como familiares. A comparação entre o trabalho de Duncan (1978 apud Wernick 2004) e o TAS de Hall (1987) gerado a partir da litogeoquímica indica que esses são produtos da cristalização fracionada de um mesmo magma (neste caso, de composição gabroica transalcalina) (Fig. 17).

O processo de cristalização fracionada também é interpretado nos diagramas de Harker $\left(\mathrm{SiO}_{2}\right.$ versus óxidos e elementos traços): à medida que o magma se cristaliza, há um empobrecimento em Fe, Mg, Ca, Mn e Ti na fase líquida. Em contrapartida, o material fracionado torna-se mais félsico e enriquecido em elementos incompatíveis, tais como $\mathrm{Na}, \mathrm{K}$, Th, Rb, Zr, Nb e Hf. O Ni e o V apresentam afinidade com os minerais máficos primeiramente cristalizados e, por isso, também estão associados a uma curva negativa.

$\mathrm{O}$ trend negativo de $\mathrm{P}_{2} \mathrm{O}_{5}$ deve-se à maior precipitação de apatita nos gabros e, em menor proporção, no quartzo sienito. Já o Sr tem grande afinidade com o plagioclásio e, como o referido mineral reduz seu volume nas rochas mais félsicas, o elemento também acompanha o processo. No caso do $\mathrm{Ti}$, acredita-se também que seu decréscimo seja reflexo da maior quantidade de ilmenita em rochas gabroicas.

Os diagramas de ETR e elementos incompatíveis das amostras analisadas da Supersuíte G5 apresentam padróes idênticos, o que torna evidente a familiaridade 

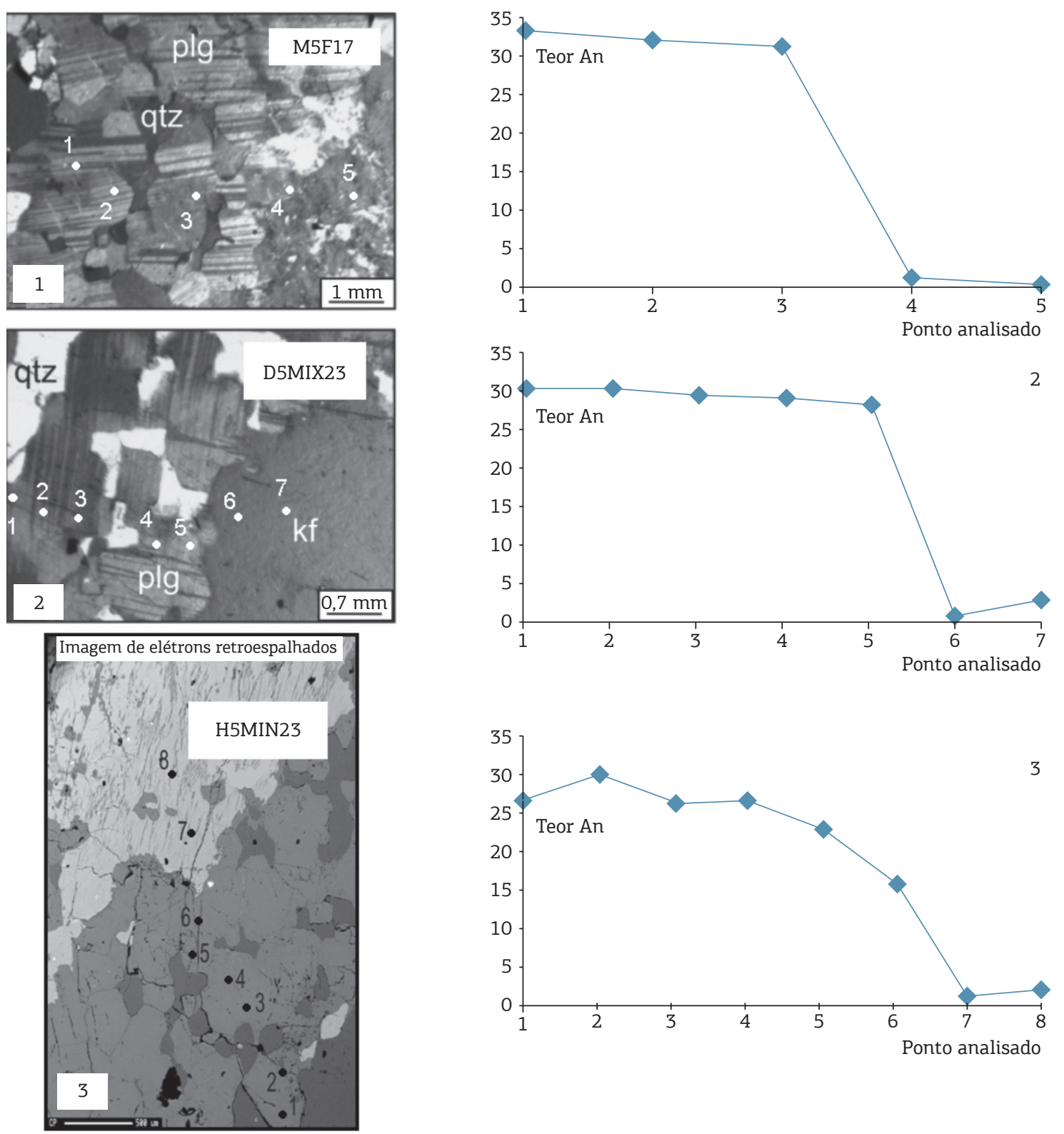

qtz: quartzo; plg: plagioclásio; kf: K-feldspato (Zanon et al. 2012).

Figura 16. Relação entre o teor de anortita e os pontos analisados na microssonda através do perfil traçado inicialmente da borda de reação até o xenocristal de K-feldspato das amostras H5MIN23, D5MIX23B e M5F17. As imagens 1 e 2 correspondem a fotografias tiradas em microscópio óptico, e a imagem 3, à imagem obtida por microssonda.

entre elas. O maior enriquecimento desses elementos no quartzo monzonito e no quartzo sienito (principalmente) complementa a questão anterior, de que durante o fracionamento do magma gabroico tais elementos migraram para fases mais félsicas, tendo em vista sua afinidade por elas. O empobrecimento em LILE, principalmente nos litotipos melanocráticos, é indício de que o magma parental foi fortemente fracionado. As anomalias negativas em P, Eu, Sr e Ti mais acentuadas em rochas leucocráticas e intermediárias, além de reforçarem essa ideia, confirmam a interpretação realizada nos diagramas de Harker. 
Os valores negativos de $\mathrm{Nb}$ e $\mathrm{Ta}$ nos litotipos melanocráticos sugerem que o magma parental (gabroico) formou-se por processos metassomáticos da cunha astenosférica em zonas de subducção, confirmando, assim, a origem mantélica dessas rochas descritas na literatura (Horn \& Weber-Diefenbach 1987, Mendes et al. 1997, Ludka et al. 1998, Medeiros et al. 2000, WiedemannLeonardos et al. 2000).

Considerando os trabalhos anteriores (WiedemmanLeonardos 2000, Weinberg et al. 2004 apud Campos et al. 2004) junto às evidências de campo e ao contexto geotectônico regional, acredita-se que as zonas de cisalhamento dextrais localizadas próximas à área de estudo auxiliaram na entrada e na forma de contorno do CISA.
Os dois núcleos máficos intrudiram na litosfera a partir de processos de diapirismo associados a tais zonas de cisalhamento (Weinberg et al. 2004 apud Campos et al. 2004) (Fig. 18A). A descompressão no vazio transtensional e o calor desses núcleos, somados às condições de deformação dúctil (registrada nas rochas encaixantes), resultaram na geração do sienogranito a partir da fusão parcial do metagranodiorito (Fig. 18B).

A movimentação dextral dessas zonas de cisalhamento deu-se concomitantemente ao soerguimento do corpo intrusivo a porçôes mais superiores da litosfera, causando a deformação das rochas encaixantes ortoderivadas e, consequentemente, gerando a forma alongada e lenticular desse enorme corpo intrusivo.

A

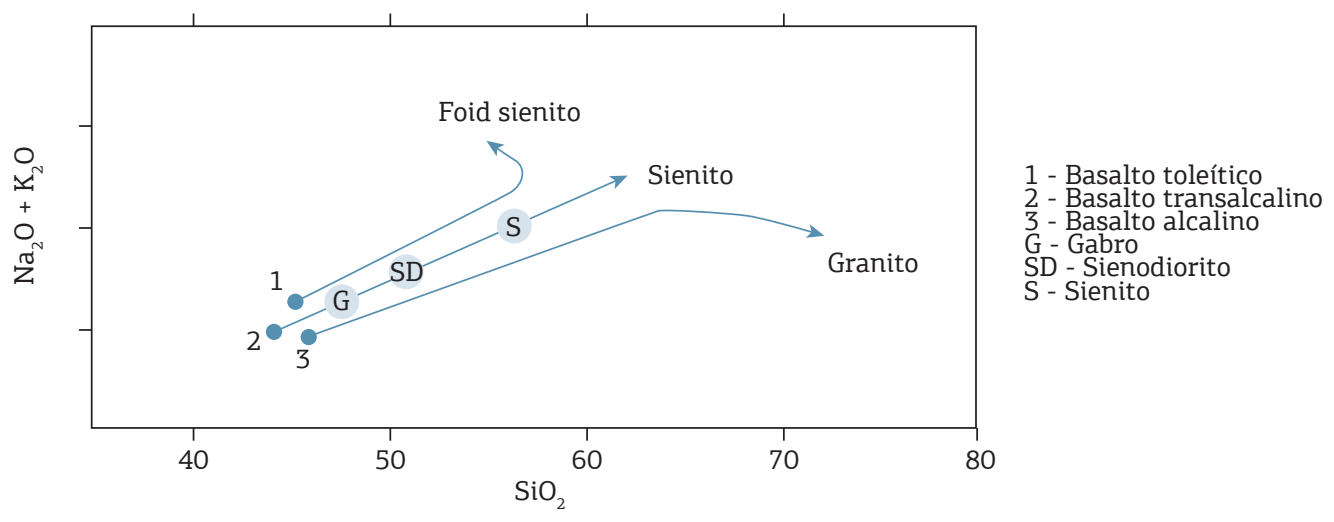

B
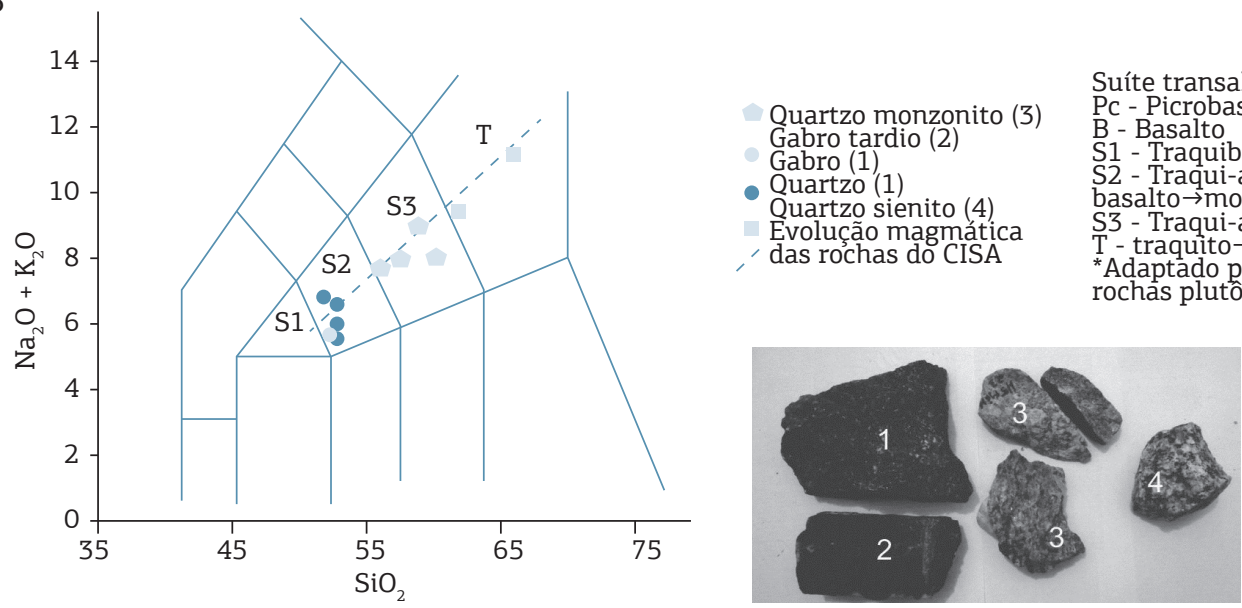

CISA: Maciço Santa Angélica.

Figura 17. Diagrama de TAS: (A) segundo Hall (1987), com a evolução das séries basálticas toleítica, alcalina transicional e alcalina sódica; (B) segundo Le Bas et al. (1986), adaptado por Middlemost (1991), com a possível evolução magmática das rochas da Supersuíte G5 do Maciço Santa Angélica a partir da cristalização fracionada de um magma de composição gabroica alcalina transicional. 
Nessa mesma fase, processos de diferenciação magmática envolvendo os núcleos de composição máfica ocorriam, resultando na formaçáo do quartzo monzonito e, por fim, do quartzo sienito (Fig. 18C).

O contato do sienogranito com os litotipos gerados a partir de tal diferenciação (quartzo sienito e quartzo monzonito) resultou na formação de uma extensa zona de mistura mecânica de magmas (mingling), envolvendo xenólitos de diferentes composiçóes e xenocristais de K-feldspato (Figs. 18C e 18 D).
Como a análise geoquímica e petrográfica do quartzo monzonito, presente na área mais homogênea da zona de mistura de magmas, indicou maior familiaridade do mesmo com os núcleos gabroicos e com o quartzo monzonito, acredita-se que o CISA não possui a fase mixing.

Acredita-se que o gabro tardio da Supersuíte G5 é produto de novas injeçóes de magma na câmara magmática que, devido às correntes de convecção, alcançavam regióes próximas ao mingling.
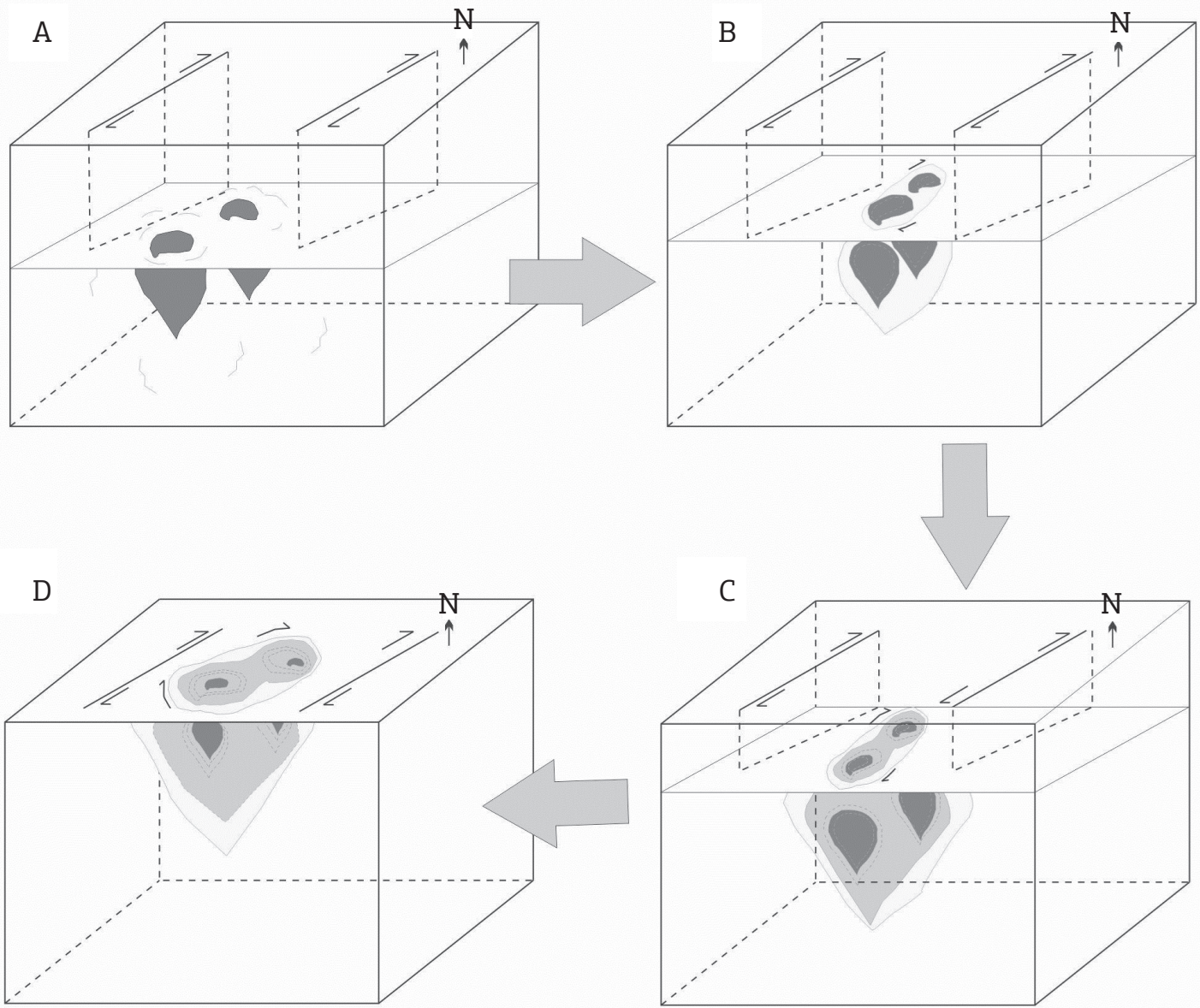

Magma gabróico

Magma mingling

Zonas de cisalhamento

Diferenciação magmática

$\square$ Magma sienogranítico

Figura 18. Esquema da evolução do Maciço Santa Angélica: (A) ascensão dos dois núcleos gabroicos e início da fusão parcial da crosta ortoderivada; (B) geração do magma sienogranítico, início da diferenciação magmática dos núcleos gabroicos e interação dos mesmos com o líquido mais félsico (início do mingling) associados às zonas de cisalhamento dextrais; $(C)$ intensificação do processo de diferenciação magmática e também da mistura mecânica entre os magmas associados às zonas de cisalhamento dextrais; (D) estruturação final do plúton. 
Tabela 3. Resultado das análises por microssonda dos perfis traçados da borda mirmequítica até os xenocristais de $\mathrm{K}$-feldspato. $\mathrm{O}$ ponto 1 corresponde ao ponto analisado mais próximo do contato borda de reação - rocha.

\begin{tabular}{|c|c|c|c|c|c|c|c|c|c|c|c|}
\hline \multirow{2}{*}{ H5MIN23 } & \multirow{2}{*}{$\mathrm{Na}_{2} \mathrm{O}$} & \multirow{2}{*}{$\mathrm{K}_{2} \mathrm{O}$} & \multirow{2}{*}{$\mathrm{Al}_{2} \mathrm{O}_{3}$} & \multirow{2}{*}{$\mathrm{CaO}$} & \multirow{2}{*}{$\mathrm{SiO}_{2}$} & \multirow{2}{*}{ Total } & \multicolumn{3}{|c|}{ Cátions } & \multirow{2}{*}{ Mineral } & \multirow{2}{*}{$\begin{array}{l}\text { Teor de } \\
\text { Anortita }\end{array}$} \\
\hline & & & & & & & $\mathrm{Na}$ & $\mathrm{Ca}$ & $\mathbf{K}$ & & \\
\hline 1 & 6,95 & 0,43 & 24,05 & 5,91 & 61,02 & 98,36 & 2,424 & 1,139 & 0,099 & PL & 31,1 \\
\hline 2 & 7,00 & 0,45 & 23,88 & 5,61 & 61,04 & 97,99 & 2,448 & 1,084 & 0,104 & PL & 29,8 \\
\hline 3 & 5,04 & 0,21 & 27,69 & 10,15 & 55,22 & 98,31 & 1,784 & 1,985 & 0,049 & PL & 52 \\
\hline 4 & 4,83 & 0,26 & 28,18 & 10,58 & 54,94 & 98,79 & 1,704 & 2,062 & 0,06 & PL & 53,9 \\
\hline 5 & 5,27 & 0,33 & 25,76 & 8,67 & 54,31 & 94,33 & 1,937 & 1,761 & 0,08 & PL & 46,6 \\
\hline 6 & 5,72 & 0,35 & 27,06 & 8,88 & 57,31 & 99,31 & 1,997 & 1,713 & 0,08 & PL & 45,2 \\
\hline 7 & 5,22 & 0,32 & 27,86 & 9,92 & 56,40 & 99,72 & 1,82 & 1,911 & 0,073 & $\mathrm{KF}$ & 50,2 \\
\hline 8 & 4,95 & 0,33 & 28,02 & 9,87 & 56,04 & 99,21 & 1,733 & 1,919 & 0,076 & $\mathrm{KF}$ & 51,4 \\
\hline \multicolumn{12}{|l|}{ D5MIX23 } \\
\hline 1 & 7,09 & 0,56 & 24,56 & 5,79 & 61,52 & 99,52 & 2,445 & 1,103 & 0,127 & PL & 30 \\
\hline 2 & 7,14 & 0,55 & 24,39 & 5,75 & 61,72 & 99,54 & 2,461 & 1,095 & 0,125 & PL & 29,7 \\
\hline 3 & 7,10 & 0,54 & 24,71 & 6,21 & 62,15 & 100,71 & 2,422 & 1,171 & 0,121 & PL & 31,5 \\
\hline 4 & 5,42 & 0,29 & 26,82 & 8,92 & 57,10 & 98,55 & 1,904 & 1,732 & 0,067 & PL & 46,8 \\
\hline 5 & 4,37 & 0,22 & 29,20 & 11,33 & 53,85 & 98,97 & 1,544 & 2,173 & 0,051 & PL & 57,7 \\
\hline 6 & 4,61 & 0,22 & 28,94 & 11,20 & 54,65 & 99,62 & 1,615 & 2,168 & 0,051 & $\mathrm{KF}$ & 56,5 \\
\hline 7 & 4,59 & 0,28 & 28,90 & 11,06 & 54,78 & 99,60 & 1,608 & 2,141 & 0,065 & $\mathrm{KF}$ & 56,1 \\
\hline \multicolumn{12}{|l|}{ M5F17 } \\
\hline 1 & 6,85 & 0,29 & 24,71 & 6,36 & 60,54 & 98,74 & 1,222 & 2,382 & 0,066 & PL & 33 \\
\hline 2 & 6,92 & 0,36 & 24,12 & 6,14 & 60,14 & 94,69 & 1,193 & 2,433 & 0,083 & PL & 32 \\
\hline 3 & 7,04 & 0,37 & 24,18 & 6,06 & 59,80 & 97,45 & 1,181 & 2,483 & 0,086 & PL & 3 \\
\hline 4 & 2,19 & 13,42 & 18,85 & 0,18 & 64,44 & 99,07 & 0,036 & 0,785 & 3,165 & $\mathrm{KF}$ & 1 \\
\hline 5 & 1,34 & 14,71 & 18,79 & 0,12 & 63,59 & 98,55 & 0,024 & 0,486 & 3,507 & $\mathrm{KF}$ & 1 \\
\hline
\end{tabular}

Os cristais de K-feldspato (oriundos do sienogranito do G5) que migraram para o quartzo monzonito e para o gabro tardio durante a formação da zona de mistura de magmas desencadearam uma reação envolvendo os íons de $\mathrm{Ca}$ e $\mathrm{Na}$ presentes na fase líquida (Becke 1908 apud Baker, 1970) (Fig. 19). Como produto final se formou a mirmequita presente nas bordas e entre as fraturas desses xenocristais em resposta à busca pelo equilíbrio entre o $\mathrm{Ca}$ da borda mirmequitica e da fase líquida (Zanon et al. 2012).

Após ou no final da geração do CISA, acredita-se que as condições geológicas regionais causaram uma nova fusão parcial das rochas da Supersuíte G1, formando, assim, o sienogranito tardio (conforme descrito na análise da litogeoquímica).

O final de todo esse processo geológico resultou na formação de um grande maciço, com dois núcleos gabroicos e bordas félsicas, estas separadas por uma extensa zona de mistura mecânica de magmas. Nessa mistura envolveram-se o

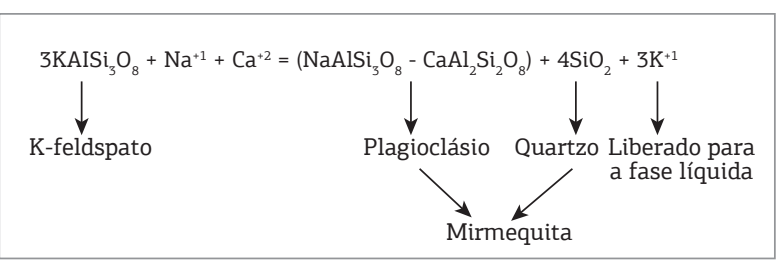

Figura 19. Equação mostrando a reação xenocristallíquido que desencadeou a formação de bordas mirmequíticas baseada na hipótese de Becke para a formação de mirmequita (adaptado de 1908 apud Baker, 1970) (Zanon et al. 2012).

sienogranito, o quartzo sienito, o quartzo monzonito e ambos os gabros, todos pertencentes à Supersuíte G5. O posicionamento desse grande corpo intrusivo acompanhou a direção e cinemática das zonas de cisalhamento locais (NE/SW) e das estruturas registradas em sua encaixante ortoderivada, dando a ele uma forma alongada e sigmoidal. 


\section{REFERÊNCIAS}

Alkmin FF. Pedrosa-Soares A.C. Noce CM. Cruz S.C.P. 2007. Sobre a evolução tectônica do Orógeno Araçuaí-Congo Ocidental. Geonomos, 15(1):25-43.

Almeida F.F.M. 1977. O Cráton do São Francisco. Revista Brasileira de Geociências, 7(4):349-364

Bayer B., Schimidt-Thomé R., Weber-Diefenbach K., Horn H.A. 1987. Complex concentric granitoid intrusions in the coastal mobile belt, Espírito Santo, Brazil: the Santa Angélica Pluton - an example. Geologische Rubdschau, 76(2):357-371.

Bayer P., Horn H.A., Lammerer B., Schmidt-Thomé R., WeberDiefenbach K., Wiedemann C. 1986. The Brasiliano Mobile Belt in southern Espírito Santo (Brazil) and its igneous intrusions. Zentralblatt für Geologie und Palæontologie, 9/10:1429-1440.

Bayer P., Schmidt-Thomé R., Weber-Diefenbach K., Horn H.A. 1987. Complex concentric granitoid intrusions in the coastal mobile belt, Espírito Santo, Brazil: the Santa Angélica Pluton - an example. Geologische Rundschau, 76(2):357-371.

Barker D.S. 1970. Granophyre, Myrmekite, and Graphic Granite. Geological Society of America Bulletin, 81:3339-3350.

Beke F. 1908. Uber Myrmekit: Tschermajs Mineralog.u. Petrog. Mitt, 27:377-390

Brito-Neves B.B., Cordani U.G. 1991. Tectonic evolution of South America during the Late Proterozoic. Precambrian Reseach, 53:23-40

Brown G.C. 1982. Mineralogy of basaltic rocks. In: Hess H.H., Poldervaart A. (Eds.). Basalts: The Poldervaart Treatise on Rocks of Basaltic Composition. New York, Wiley Interscience, 1, p. 103-162.

Campos C.M., Mendes J.C., Ludka I.P., Medeiros S.R., Moura J.C., Wallfass C. 2004. A review of the Brasiliano magmatism in southern Espírito Santo, Brazil, with emphasis on postcollisional magmatism. Journal of the Virtual Explorer, 17(1):35.

Campos Neto M.C. \& Figueiredo M.C.H. 1995. The Rio Doce Orogeny, Southeastern Brazil. Journal of South America Earth Science, 8:143-162.

Collins L.G. 1996. Citação de referencias e documentos eletrônicos. Disponível em: http://www.csun.edu/ vcgeo005/index.html. Acesso em: 4 ago. 2012

CPRM. 2013. Mapa Geológico do Estado do Espírito Santo.

Duncan A.M. 1978. Thetrachybasaltic volcanic of the Adrano area, Mount Etna, Sicily. Geological Magazine, 115:273-285.

Ebert H., Hasui Y. 1998. Transpressional tectonics and strain partitioning during oblique collision between three plates in the Precambrian of southeast Brazil. In: Holdsworth R.E., Stranchan R.A., Dewey J.F. (Eds.). Continental transpressional and transtensional tectonics. London, The Geological Society of London, p. 231-252. (Special Publication)

Geiger A. 1993. Die Geologie des Steinbruchreviers von Cachoeiro de Itapemirim Südliches Espírito Santo, Brasilien. Münchener Geowissenschaftliche, München, Friedrich Pfeil Verlag, 217 p.

Geobank - Serviço Geológico do Brasil. Disponível em: http:// geobank.sa.cprm.gov.br/. Acesso em: 9 nov. 2009.

Google Maps. Disponível em: maps.google.com.br/. Acesso em: 5 maio 2009.

Hall A. 1987. Igneous Petrology. Longman Scientific and Tecnical. New York, John Wiley \& Sons, Inc., 573 p.
Heilbron M., Pedrosa-Soares A.C., Campos-Neto M.C., Silva L.C. Trouw R., Janasi V.A. 2004. Província Mantiqueira. In: V. MantessoNeto, A. Bartorelli, C.D.R. Carneiro, B.B. Brito-Neves (eds.). Geologia do Continente Sul-Americano. Editora Beca, São Paulo, p. 203-234.

Horn A.H. 2006. Geologia da Folha Espera Feliz 1:100.000. Rio de Janeiro, CPRM - Serviço Geológico do Brasil, UFMG - Programa Geologia do Brasil.

Horn H.A., Weber-Diefenbach K., 1987. Geochemical and genetic studies of three inverse zoned intrusive bodies of both alkaline and subalkaline composition in the Araçuaí-Ribeira Mobile Belt (Espírito Santo, Brazil). Revista Brasileira de Geociências, 17:488-497.

IBGE - Instituto Brasileiro de Geografia e Estatística. 1978. Mapa Topográfico de Anutiba (ES) - Folha SD-24-V-A-V-1. Escala 1: 50.000.

Irvine T.N. \& Baragar W.R.A. 1971. A guide to the chemical classification of the common volcanic rocks. Canadian Journal of Earth Sciences, 8:523-48.

Kelemen P.B., Shumizu N., Dum T. 1993. Relative depletion of niobium in some arc magmas and the continental crust: partitioning of $\mathrm{K}, \mathrm{Nb}$, La, Ce during melt/rock reaction in the upper mantle. Earth and Planetary Science Letters, 120:11-134

Kisters F.M., Jordaan L.S., Neumaier K. 2004. Thrust-related dome structures in the Karibib district and the origin of orthogonal fabric domains in the south Central Zone of the Pan-African Damara belt, Namibia. Precambrian Reseach, 133:283-303.

Le Bas M.J., Le Maitre R.W., Streckeisen A., Zanettin B. 1986. A chemical classification of volcanic rocks based on the total alkalisilica diagram. Journal of Petrology, 27:745-750.

Maniar P.D. \& Piccoli P.M. 1989. Tecnotic discrimination of granioids Geological Society of America Bulletin, 101:635-643.

Middlemost E.A.K. 1991. Towards a comprehensive classification of igneous rocks and magmas. Earth-Science Reviews, 31:73-87.

Nalini Junior H. A. 1997. Caractérisation des suites magmatiques néoprotérozoïques de la region de Conselheiro Pena et Galiléia (Minas Gerais, Brésil). Etude géochimique et structurale des Supersuítes Galiléia et Urucum et relations avec les pegmatites à éléments rares associées. Tese de Doutorado, Ecole des Mines de Saint Etienne et Ecole des Mines de Paris, 237 p.

Nalini Junior H.A., Bilal E., Paquette J.L., Pin C. \& Machado R. 2000 Geochronologie $\mathrm{U}-\mathrm{Pb}$ et géochimie isotopique $\mathrm{Sr}-\mathrm{Nd}$ des granitoides neoproterozoiques des suites Galileia et Urucum, vallée du Rio Doce, Sud-Est du Brésil. Compte Rendu Academie Science Paris, 331:459-466.

Nalini Junior H.A., Bilal E., Correia-Neves J.M. 2000. Syncollisional peraluminous magmatism in the Rio Doce region: mineralogy, geochemistry and isotopic data of the Urucum suite (eastern Minas Gerais State, Brazil). Revista Brasileira de Geologia, 30:120-125.

Nalini Junior H.A., Machado R.M., Bilal E. 2005. Geoquímica e petrogênese da Supersuíte Galiléia: exemplo de magmatismo tipo-I, metaluminoso, pré-colisional, neoproterozóico, da região do Médio Vale do Rio Doce. Revista Brasileira de Geologia, 35(4-suplemento):23-34

Nanni A.S. \& Chaves A.O. 2011. Uso de aplicativos computacionais livres em disciplinas de mapeamento geológico. GeoFocus, 11:55-65. (Informes y comentários).

Noce C.M., Macambira M.J., Pedrosa-Soares A.C. 2000. Chornology of Neoproterozóico-Cambrian granitic magmatism in the Araçuaí Belt, eastern Brazil, based on single zircon evaporation dating. Revista Brasileira de Geologia, 30:25-29. 
Nesbitt H.W. \& Young G.M. 1982. Early Proterozoic climates and plate motions inferred from major element chemistry of lutites. Nature, 299(82):715-717.

Pearce T.H. 1968. A contribution to the theory of variation diagramas. Contributions to Mineralogy and Petrology, 19:142-157.

Pearce J.A., Harris N.B.W., Tindle A.G. 1984, Trace element discrimination diagrams for the tectonic interpretation of granitic rocks: Journal of Petrology, 25:956-983.

Pedrosa-Soares A.C. 1995. Evidências da terminação setentrional do Oceano Adamastor (Neoproterozóico) no sudeste brasileiro. In: SBG - SRS, Encuentro de Geologia del Cono Sur, I, 1995, Anais (Palestras convidadas), p. 37-48.

Pedrosa-Soares A.C. 1997. Geologia da Folha Araçuaí. In: Grossi-Sad J.H., Lobato L.M., Pedrosa-Soares A.C., Soares-Filho B.S. (Org.). Projeto Espinhaço em CD-ROM, 1a edição. Compania Mineradora de Minas Gerais, Belo Horizonte, 1997, p. 715-852.

Pedrosa-Soares A.C. 1997. Geologia da Folha Jenipapo. In: J GrossiSad J.H., Lobato L.M., Pedrosa-Soares A.C., Soares-Filho B.S. (Org.). Projeto Espinhaço em CD-ROM, $1^{a}$ edição. Belo Horizonte, Companhia Mineradora de Minas Gerais, p. 1052-1198.

Pedrosa-Soares A.C., Noce C.M., Vidal P., Monteiro R., Leonardos O.H. 1992. Toward a new tectonic model for the Late Proterzoic Araçuaí (SE Brazil) - West Congolian (SW Africa) Belt. Journal of South American Earth Sciences, 6:33-47.

Pedrosa-Soares A.C. \& Oliveira M.J.R. 1997. Geologia da Folha Salinas. In: Grossi-Sad J.H., Lobato L.M., Pedrosa-Soares A.C., Soares-Filho B.S. (Eds.). Projeto Espinhaço em CD-ROM. Belo Horizonte, CODEMIG, p. 419-542.

Pedrosa-Soares A.C. \& Noce C.M. 1998. Where is the suture zone of the Neoproterozoic Araçuaí-West-Congo orogen? In: UFOP, Conference on Basement Tectonics, 14, Extended Abstracts, p. 35-37.

Pedrosa-Soares A.C., Wiedemann C.M., Fernandes M.J.S., Faria L.F., Ferreira J.C.H. 1999. Geotectonic significance of the Neoproterozoic granitic magmatism in the Araçuaí Belt, eastern Brazil: a model and pertinent questions. Revista Brasileira de Geociências, 29(1):59-66.

Pedrosa-Soares A.C. \& Wiedemann-Leonardos. 2000. Evolution of the Araçuaí Belt and its connection to the Ribeira Belt, eastern Brazil. In: Cordani E.J., Milani A., Thomaz-Filho D.A., Campos D.A. (Org.). Tectonic Evolution of South America. São Paulo, SBG, p. 265-285.

Pedrosa-Soares A.C., Noce C.M., Wiedemann C.M., Pinto C.P. 2001. The Araçuaí-West Congo orogen in Brazil: An overview of a confined orogen formed during Gondwanland assembly. Precambrian Research, 110:307-323.

Pedrosa-Soares A.C., Noce C.M., Alkmin F.F., Silva L.C., Cordani U.G., Marshak S., Whittington A., Martins-Neto M.A., Campos C.M.P. 2003. Orógeno confinado: conceito, exemplos e candidatos. In: SBG, Simpósio Nacional de Estudos Tectônicos, IX, Anais, p. 36-39.

Pedrosa-Soares A.C., Castañeda C., Queiroga G., Gradim C., Belém J., Roncato J., Novo T., Dias P., Gradim D., Medeiros S., Jacobsohn T., Babinski M. \& Vieira V. 2006. Magmatismo e tectônica do Orógeno

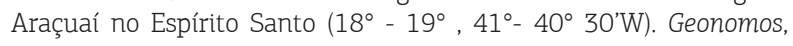
16:97-111.

Pedrosa-Soares A.C., Noce C.M., Alkmim F.F., Silva L.C., Babinski M., Cordani U., Castañeda, C. 2007. Orógeno Araçuaí: Síntese do conhecimento 30 anos após Almeida. Geonomos, 15(1):01-16.

Pedrosa-Soares A.C., Roncato J., Castañeda C., Queiroga G., Belém J., Gradim C., Novo T., Dias A.H.A., Gradim D., Medeiros S., Jacobsohn T., Costa A.G. 2008. Geologia e recursos minerais da região coberta pelas folhas Ecoporanga, Mantena, Montanha e Nova VenéciaES (Programa Geologia do Brasil, contrato CPRM-UFMG). In: SBG, Congresso Brasileiro de Geologia, 44, Anais, p. 11.
Pedrosa-Soares A.C., Campos C.P., Noce C., Silva L.C., Novo T., Roncato J., Medeiros S., Castañeda, Queiroga G., Dantas E., Dussin I., Alkimim F. 2011. Late Neoproterozoic-Cambrian granitic magmatism in the Araçuaí orogen (Brazil), the Eastern Brasilian Pegmatite Province and related mineral resources. Geological Society, 350:25-51.

Ragland P.C. 1989. Basic Analitical Petrology. Oxford, Oxford University Press, 369 p.

Richard L.R. 1988 - 1996. Minpet - Minelarogical and Petrological Data Processing System.

Rollinson H.R. 1993. Using Geochemical Data: Evaluation, Presentation, Interpretation. Edinburg, Pearson Education Limited, $315 \mathrm{p}$.

Schmidt-Thomé R. 1987. Der Santa Angelica Pluton im Araçuaí-Ribeira Mobile Belt, südliches Espírito Santo, Brasilien: Magmenmischung in einem invers zonierten Pluton. Unpub. Tese de doutorado, München, Ludwig-Maximilians-Universität, 191 p.

Schmidt-Thomé R. \& Weber-Diefenbach K. 1987. Evidence for frozen-in magma mixing in Brasiliano calc-alkaline intrusions. The Santa Angélica pluton, southern Espírito Santo, Brazil. Revista Brasileira de Geociências, 17:498-506.

Sgarbi P.B.A. Rochas Magmáticas. In: G.N.C. Sgarbi (org). Petrologia macroscópica das rochas ígneas, sedimentares e metamórficas. Belo Horizonte, Editora UFMG, p. 165-272.

Shand S.J. 1949. Eruptive rocks.New York, Wiley \& Sons, 444 p.

Sluitner Z., Weber-Diefenbach K. 1989. Geochemistry of charnoeoderbitic granulites and associated amphibolitic gneisses in the coastal region of Espírito Santo, Brazil. Zentralblatt ror Geologie und Palaontologie, 1(5-6):917-931.

Söllner F., Weber-Diefenbach K., Lammerer B. 1991. Die Krustenentwicklung in der Küstenregion nördlich von Rio de Janeiro: Altersbestimmungen (U-Pb an Zirkonen und $\mathrm{Rb}-\mathrm{Sr}$ an Gesteinen) an hochdruck- und -temperaturfaziellen Gesteinen des Ribeira Mobile Belt und des Sao Francisco Kratons (Espirito Santo/Minas Gerais). Münchner Geologische Hefte, 4, 100 p.

Sollner E., Lammerer B. and Wiedemann-Leonardos C.M. 2000. Dating the Ribeira Mobile Belt of Brazil. In: Sonderheft, Zeit. f. Angw. Geol., Hannover, p. 245-255.

Sommer C.A., Lima E.F., Nardi L.V.S., Liz J.D., Waichel B.L. 2006. The evolution of Neoproterozoic magmatismo in Southernmost Brasil: shoshonitic, hight-K, tholeitic and silica-satured, sodic alkaline volcanism in post-collisional basis. Anais da Academia Brasileira de Ciências, 78(3):573-589.

Streckeisen A.L. 1967. Classification and nomenclature of igneous rocks. Final report of an inquiry. Neues Jahrbuch fur Mineralogie, Abhandlungen, 107:144-240.

Wernick E. 2004. Rochas magmáticas: conceitos fundamentais e classificação modal, química, termodinâmica e tectônica. São Paulo, Editora UNESP, $655 \mathrm{p}$.

Whittington A.G., Connelly J., Pedrosa-Soares A.C., Marshak S., Alkmim F.F. 2001. Collapse and melting in a confined orogenic belt: Preliminary results from the Neoproterozoic Araçuaí belt of eastern Brazil. American Geophysical Union Meeting, 82:1181-1182.

Wiedemann C. 1993. The evolution of the early Paleozoic, late to post-collisional magmatic arc of the Coastal Mobile Belt, in the State of Espírito Santo, eastern Brazil. Anais da Academia Brasileira de Ciências, 65:163-181.

Wiedemann C.M., Bayer P., Horn H., Lammerer B., Ludka I.P., Schmidt-Thomé R., Weber-Diefenbach K. 1986. Maciços intrusivos do sul do Espírito Santo e seu contexto regional. Revista Brasileira de Geociências, 16:24-37. 
Wiedemann C.M., Penha H.M., Schimidt-Thomé R. 1987. Granitóides do Espírito Santo and Rio de Janeiro States. Revista Brasileira de Geociências, 17(4):674-689.

Wiedemann C., Mendes J.C., Moura J.C., Costa Nascimento R.C., Ludka I.P. 1997. Granitoids of the Espírito Santo Magmatic Arc. In: ISGAM, International Symposium on Granites and associated mineralizations, 2, Excursions Guide, p. 57-76.

Wiedemann-Leonardos C.M., Ludka I.P., Medeiros S.R., Mendes J.C., Costa-de-Moura J. 2000. Arquitetura de plutons zonados da Faixa Araçuaí-Ribeira. Geonomos, 15(1):25-38.

Wiedemann C.M., Medeiros S.R., Mendes J.C., Ludka I.P., Moura J.C. 2002. Architecture of Late Orogenic Plutons in the Aracuaí-Ribeira Folded Belt, Southeast Brazil. Gondwana Research, 5(2):381- 399.

Wilson J.T. 1966. Did the Atlantic close and then reopen? Nature, 211:676-681.

Wilson M. 1989. Igneous petrogenesis: a global tectonic approach. London: Unwin Hyman, 466 p.
Winchester J.A. \& Floyd P.A. 1977. Geochemical discrimination of different magma series and their differentiation products using immobile elements. Chemical Geology, 20:325-343.

Wood D.A., Joron J.L., Treuil M. 1979. A re-appraisal of the use og trace elements to classify and discriminate between magmas series erupted in different tectonic setting. Earth and Planetary Science Letters, 45:326-336

Zanon M.L., Chaves A.O.A, Gabrig C.V.T. 2012. A origem das bordas de mirmequita nos xenocristais de feldspato potássico em rochas máficas e híbridas do Maciço Santa Angélica - ES. Geonomos, 20(2):23-33.

Zanon M.L. 2013. A Geologia do Maciço Santa Angélica e suas encaixantes (Espírito Santo). Dissertação (Mestrado), Instituto de Geociências, Universidade Federal de Minas Gerais. 133 p.

Zhou J.B. \& Liu X.H. 2006. GeoPlot: an Excel VBA Program for Geochemical Data Ploting. Computers \& Geosciences, 32:554-560.

Arquivo digital disponível on-line no site www.sbgeo.org.br 